\title{
Synthesis of Pipecolic Acid-Based Spiro Bicyclic Lactam Scaffolds as $\beta$-Turn Mimics
}

\author{
Ravindranadh V. Somu and Rodney L. Johnson* \\ Department of Medicinal Chemistry, University of Minnesota, \\ 308 Harvard St. SE, Minneapolis, Minnesota 55455
}

\section{Supporting Information}

\section{Table of Contents}

General Experimental Methods $\quad$ S2

Proton NMR spectrum of $8 \quad$ S3

Carbon NMR spectrum of 8

Proton NMR spectrum of $\mathbf{9} \quad$ S5

Carbon NMR spectrum of $\mathbf{9}$ S6

Proton NMR spectrum of $\mathbf{1 1} \quad$ S7

Carbon NMR spectrum of $\mathbf{1 1}$ S8

Proton NMR spectrum of $\mathbf{1 4}$ S9

Carbon NMR spectrum of $\mathbf{1 4} \quad$ S10

Proton NMR spectrum of $\mathbf{1 5}$ S11

Carbon NMR spectrum of $\mathbf{1 5} \quad \mathrm{S} 12$

Proton NMR spectrum of $\mathbf{1 7} \quad$ S13

Carbon NMR spectrum of $\mathbf{1 7} \quad$ S14

Proton NMR spectrum of $\mathbf{4 a} \quad \mathrm{S} 15$

Carbon NMR spectrum of 4a $\quad$ S16

Proton NMR spectrum of $\mathbf{4 b} \quad \mathrm{b} 17$

Carbon NMR spectrum of $\mathbf{4 b} \quad$ S18

Proton NMR spectrum of $\mathbf{4 c} \quad \mathbf{c} 19$

Carbon NMR spectrum of $\mathbf{4 c} \quad$ S20

2D-NOESY spectrum of $\mathbf{4 c} \quad$ S21

Proton NMR spectrum of $\mathbf{4 d} \quad$ S22

Carbon NMR spectrum of 4d $\quad$ S23

2D-NOESY spectrum of $\mathbf{4 d} \quad$ S24

Proton NMR spectrum of 19a $\quad$ S25

Carbon NMR spectrum of 19a $\quad$ S26

Proton NMR spectrum of 19b $\quad$ S27

Carbon NMR spectrum of 19b $\quad$ S28

Proton NMR spectrum of 20a $\quad$ S29

Carbon NMR spectrum of 20a $\quad$ S30

Proton NMR spectrum of 20b S31

Carbon NMR spectrum of 20b $\quad$ S32

Proton NMR spectrum of 21a S33

Carbon NMR spectrum of 21a $\quad$ S34 
Proton NMR spectrum of 21b S35

Carbon NMR spectrum of 21b S36

Proton NMR spectrum of $22 \quad$ S37

Carbon NMR spectrum of 22

Proton NMR spectrum of $\mathbf{2 2 \cdot H C l} \quad$ S39

Carbon NMR spectrum of $\mathbf{2 2} \cdot \mathbf{H C l} \quad \mathrm{S} 40$

Proton NMR spectrum of $\mathbf{2 3} \quad$ S41

Carbon NMR spectrum of $23 \quad$ S42

Proton NMR spectrum of $\mathbf{2 4}$ S43

Carbon NMR spectrum of $\mathbf{2 4}$ S44

1D NOE spectra of $24 \quad$ S45 \& S46

General Experimental Methods. Thin-layer chromatography was perofmed on $250 \mu \mathrm{m}$ silica gel HLF Uniplates and visualization was carried out either by $\mathrm{UV}, \mathrm{I}_{2}$, anisaldehyde spray, ninhydrin spray (amines), 2,6-dichlorophenol, indophenol spray (acids), or 2,4-dinitrophenylhydrazine (aldehydes). Chromatographic purification was done by flash or gravity methods using silica gel (grade 60, 240400 mesh, 60 Å) or with Ready Sep ${ }^{\circledR}$ prepacked silica gel cartridges. 


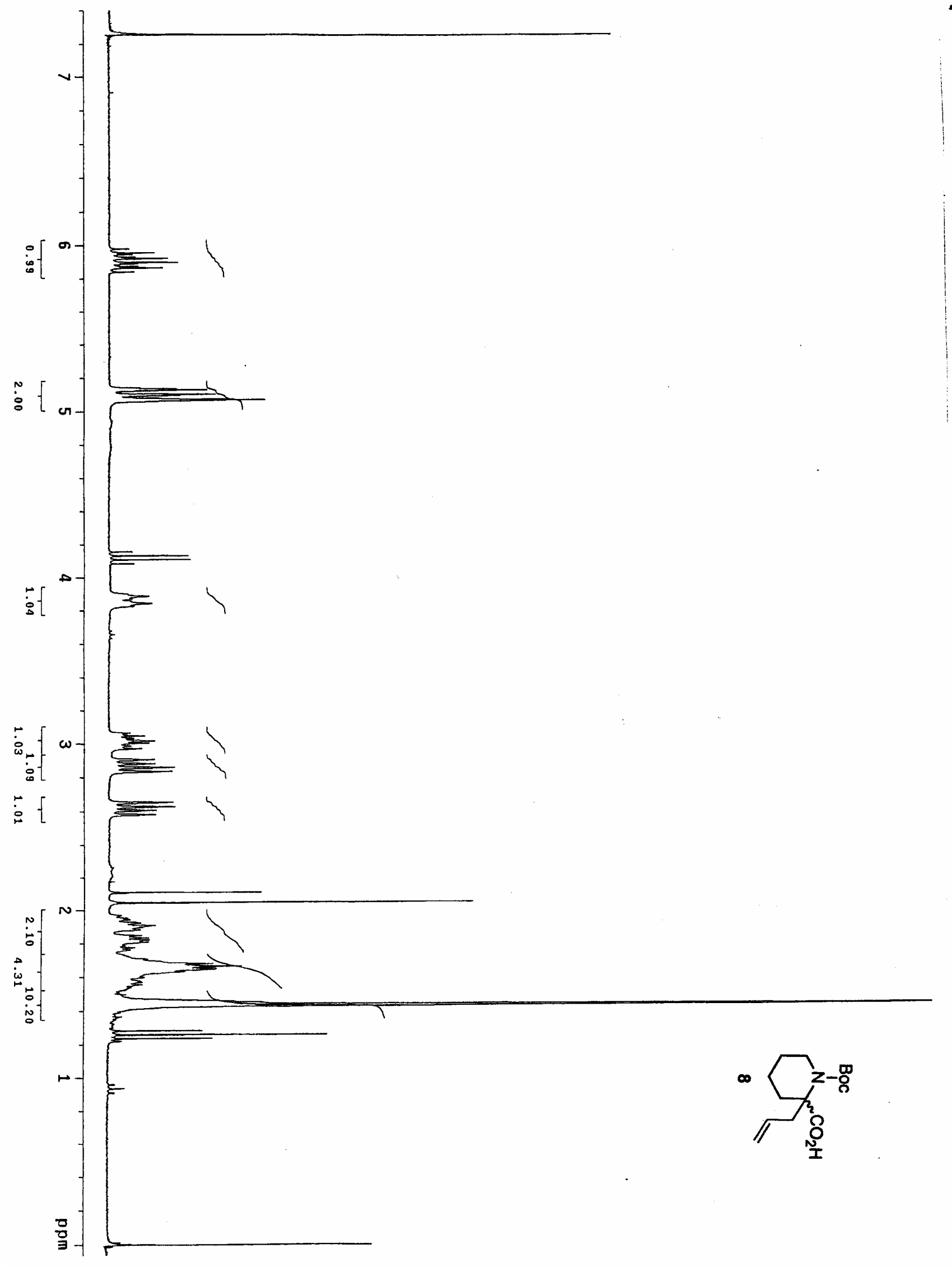




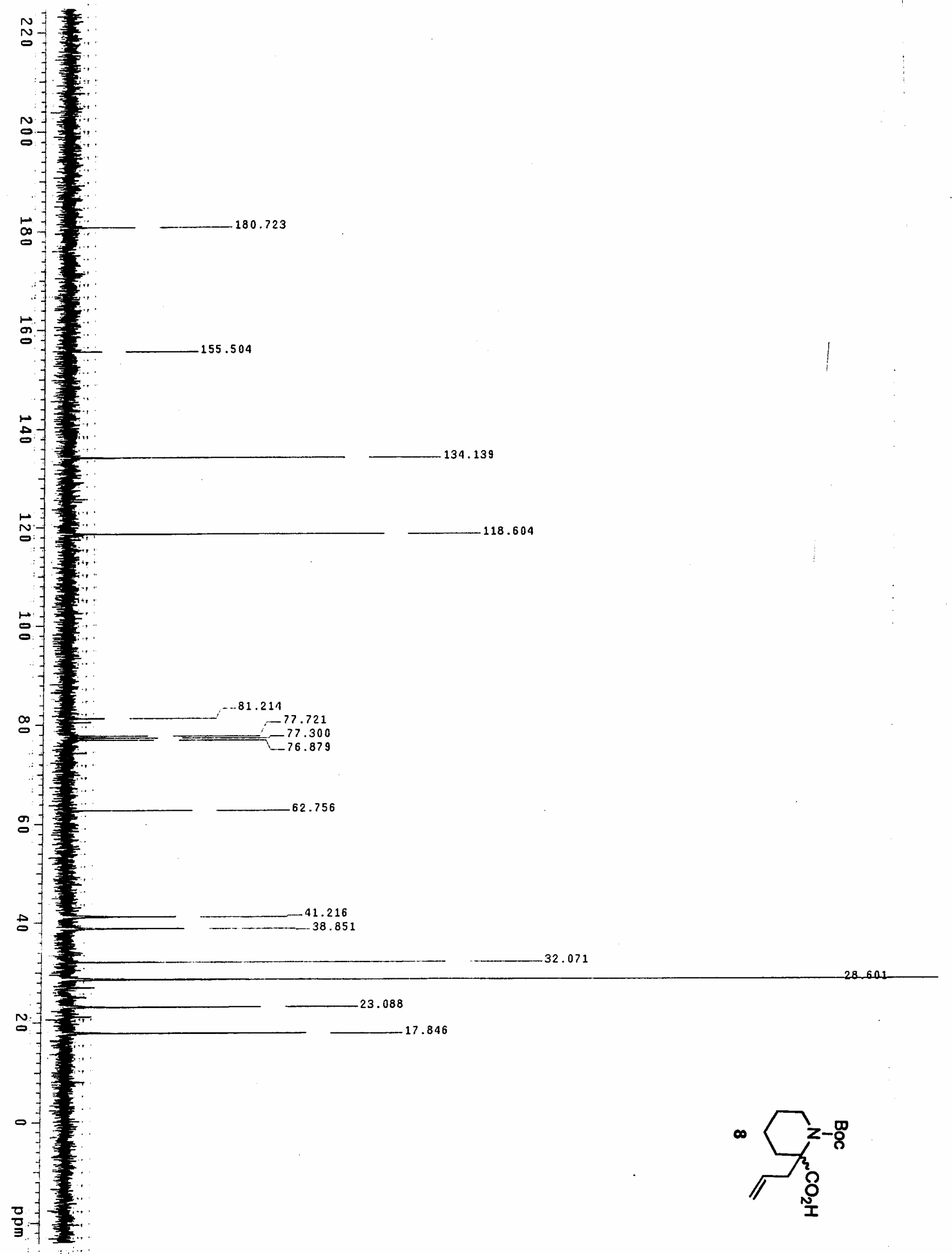




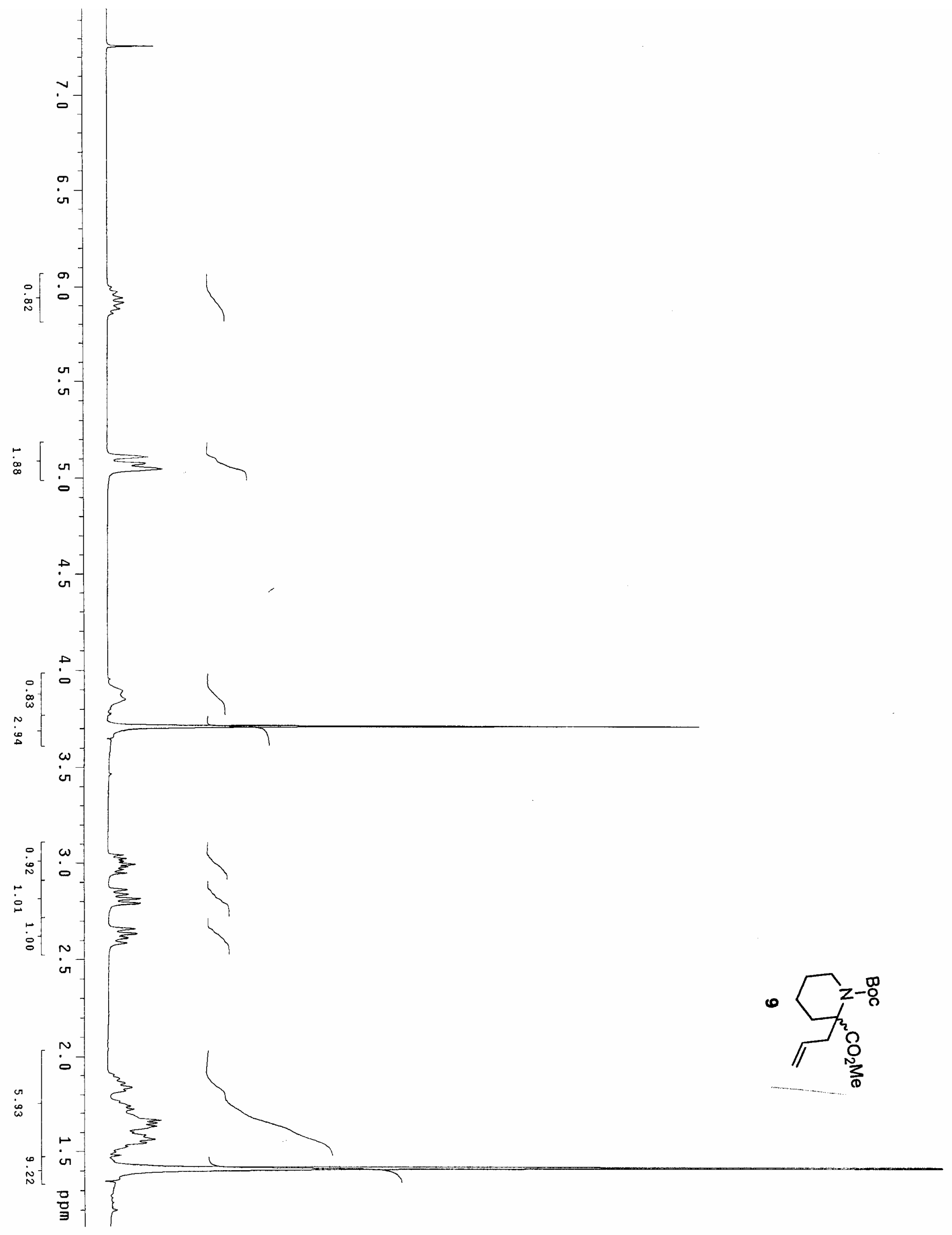




$$
\mid
$$




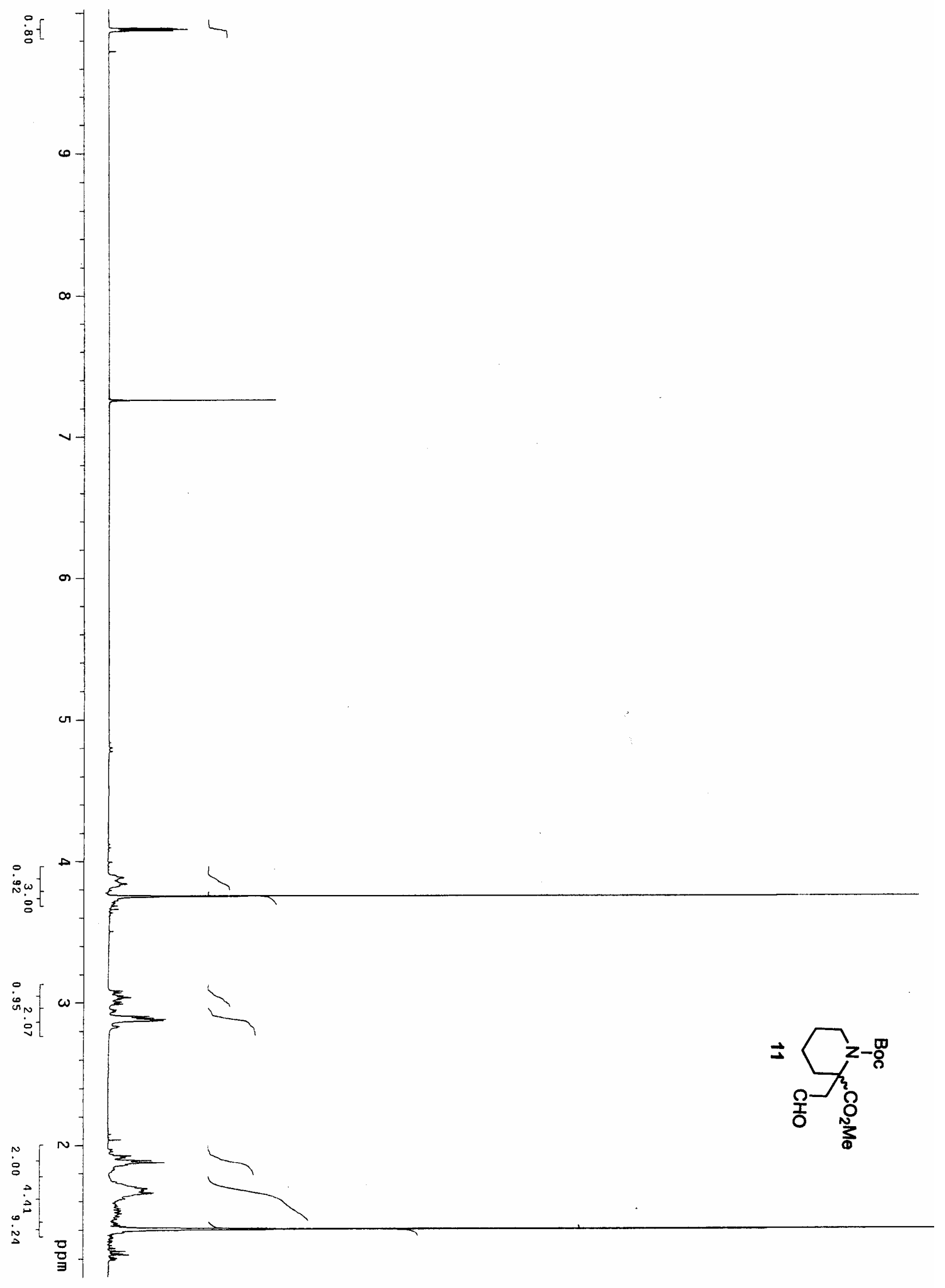




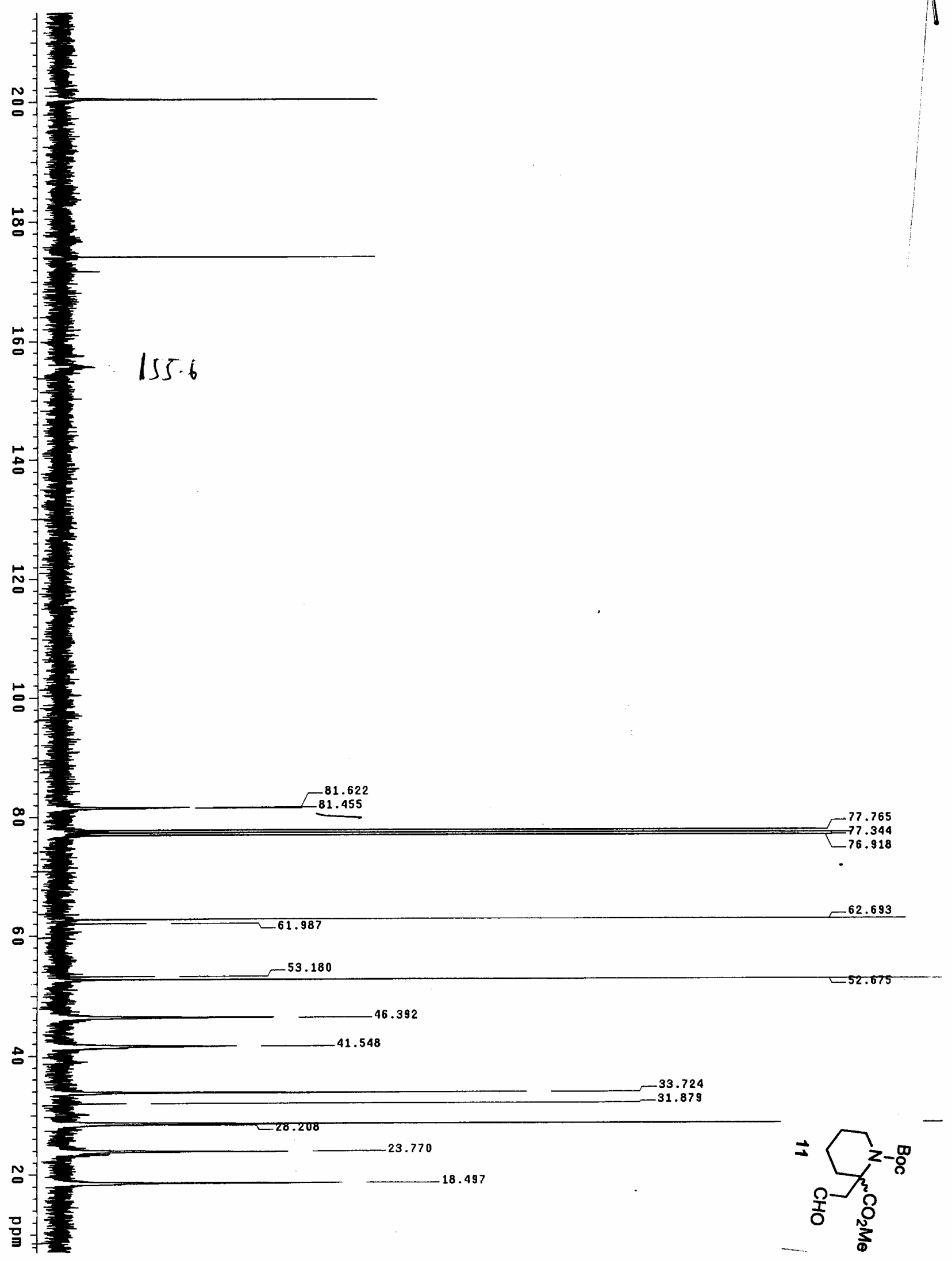




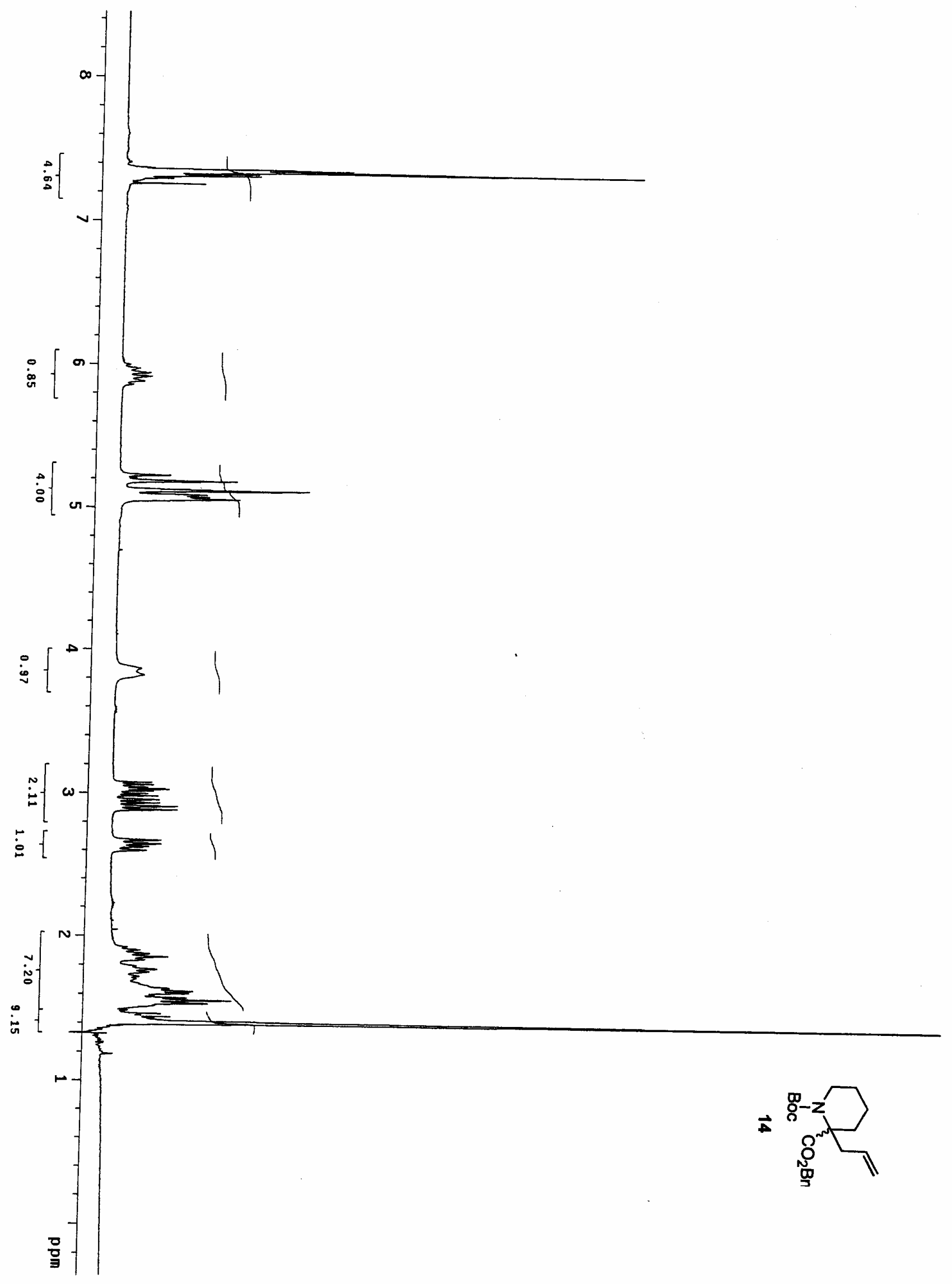




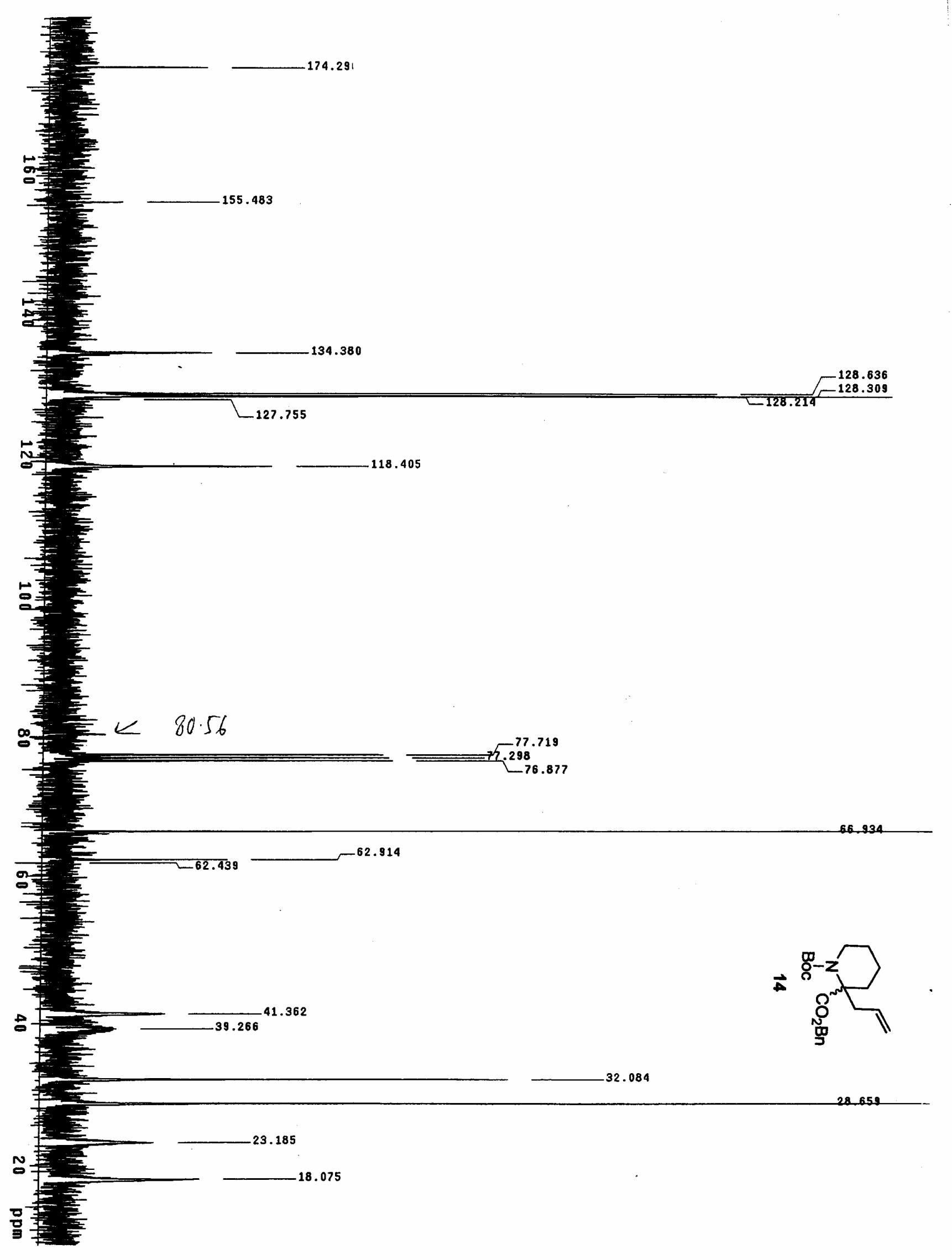




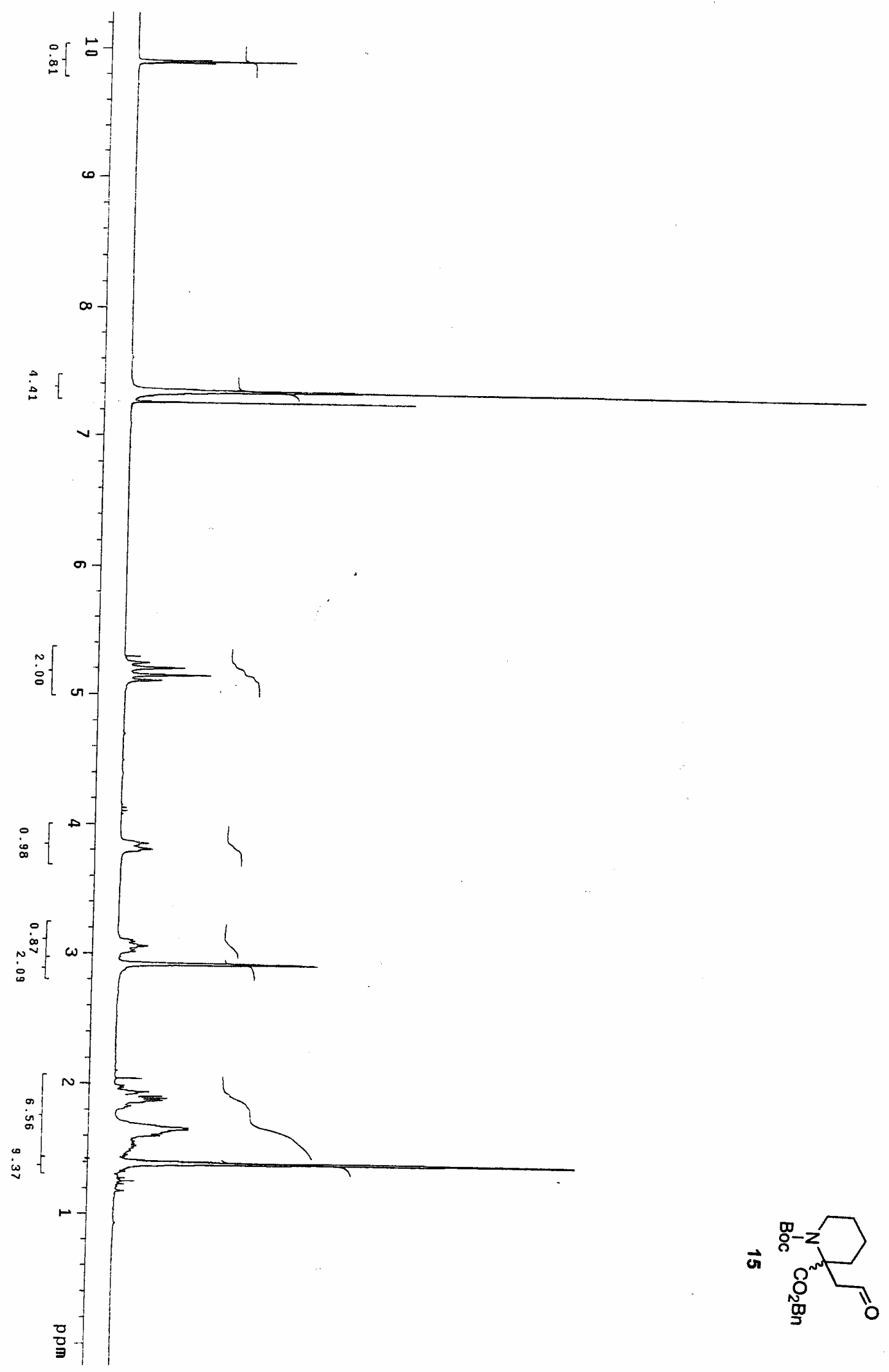

S11 


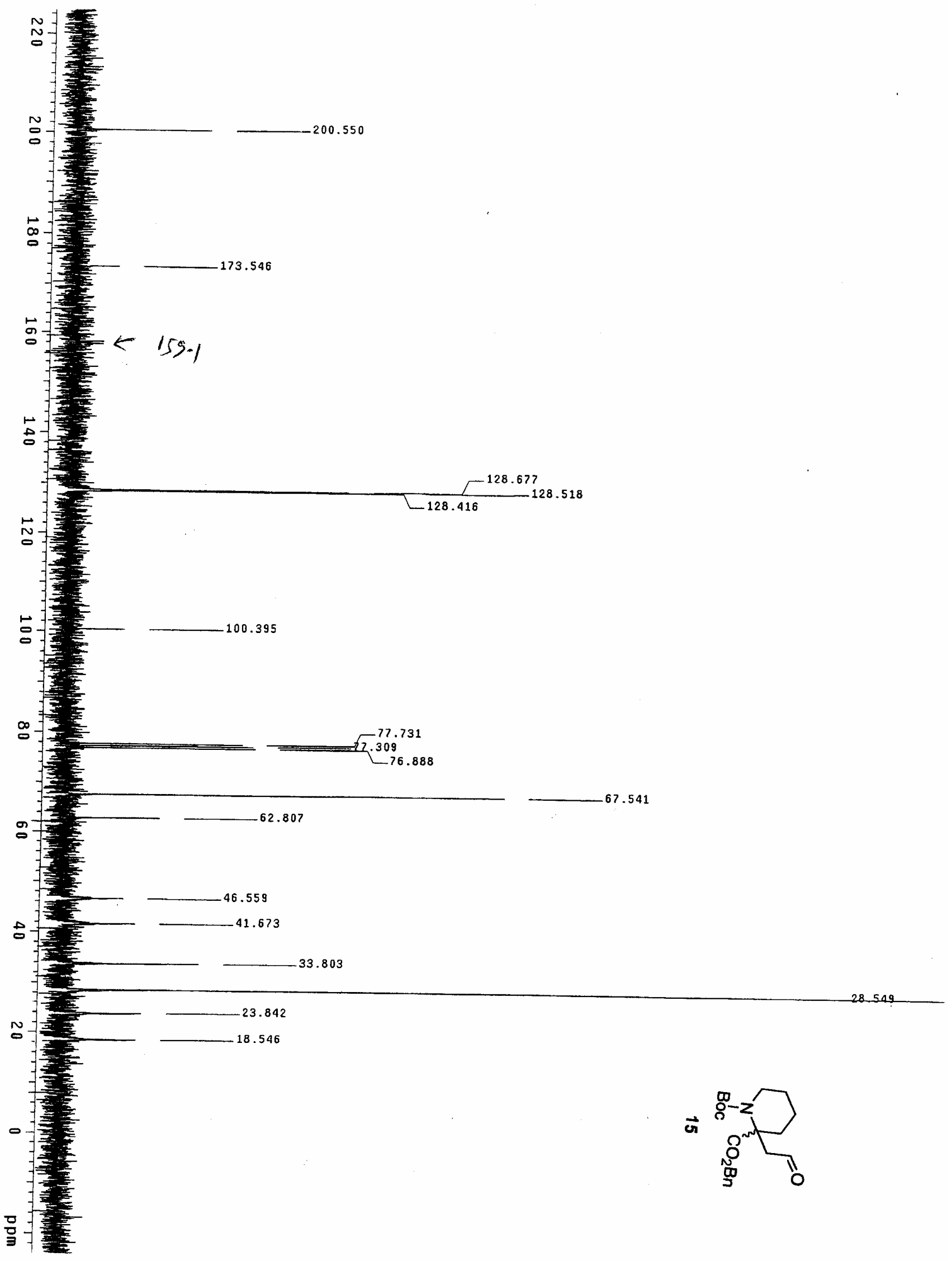




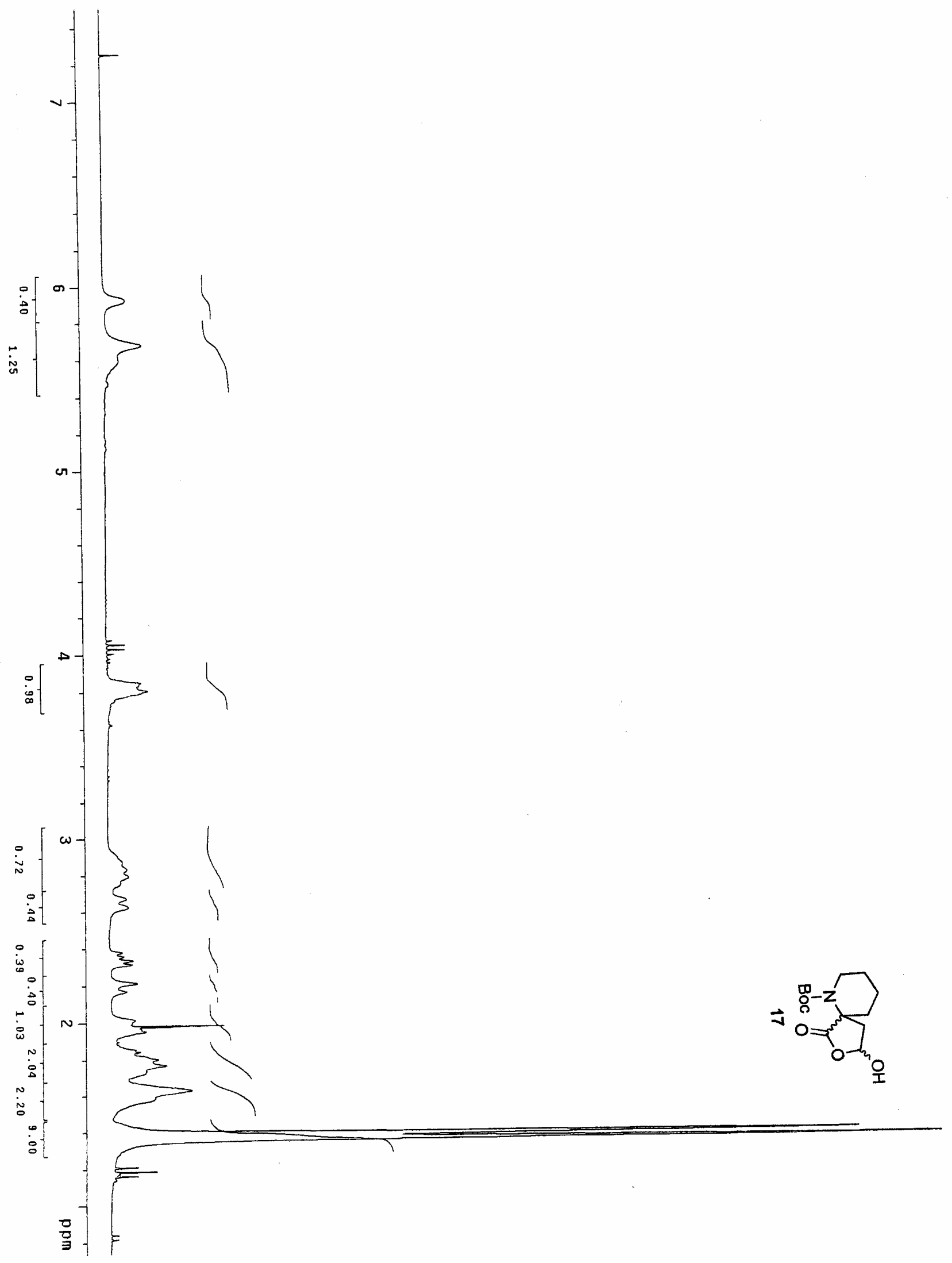




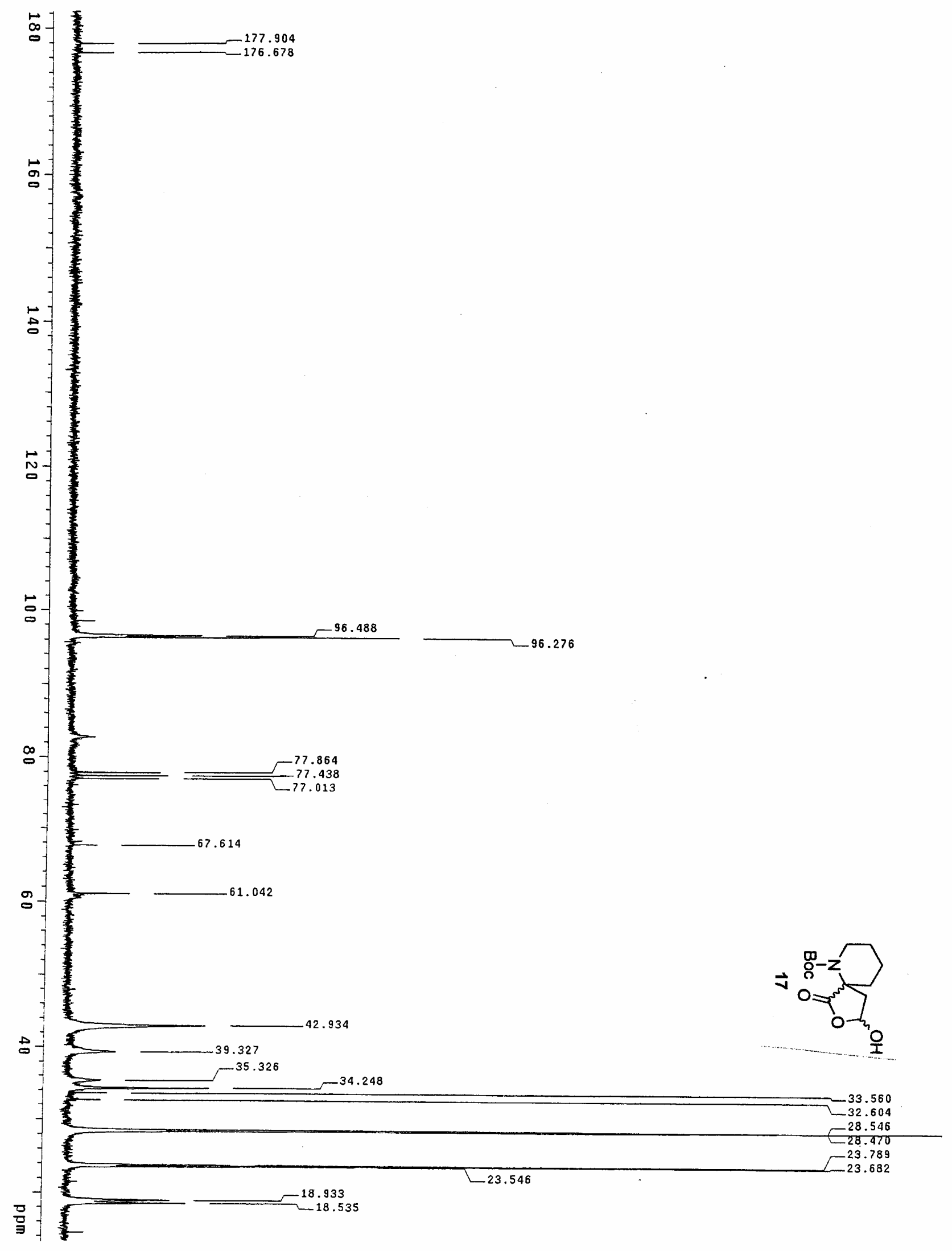




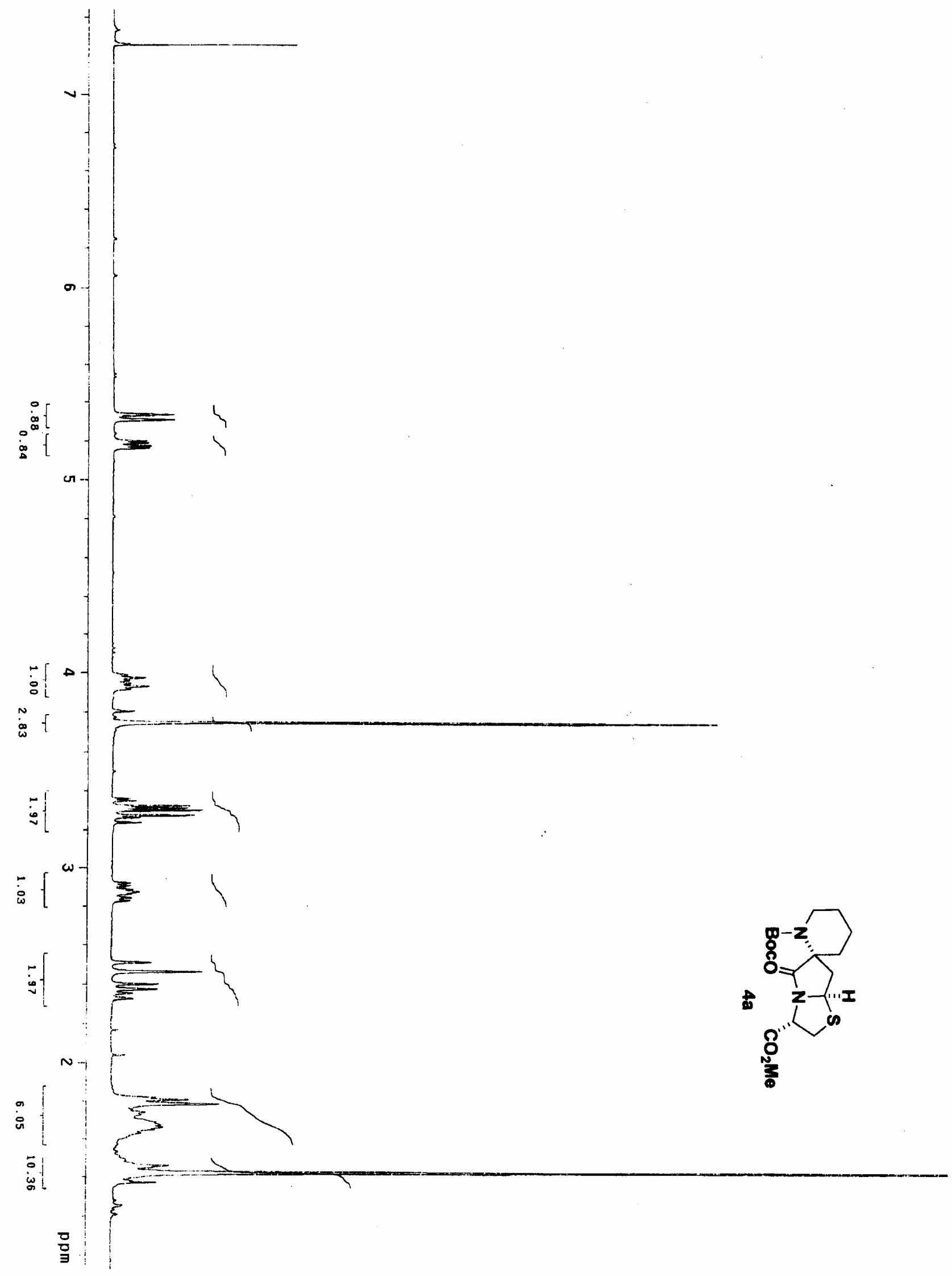




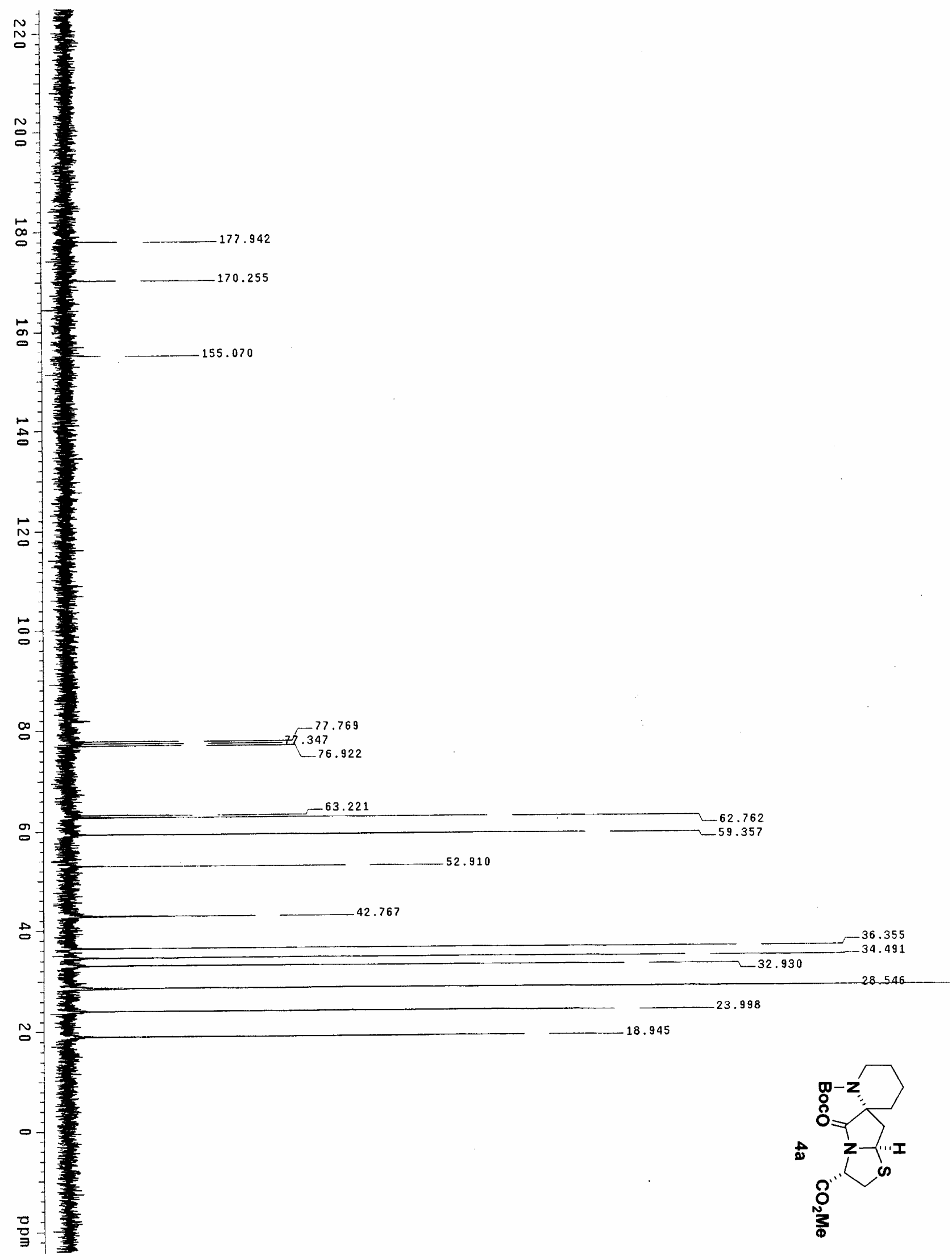




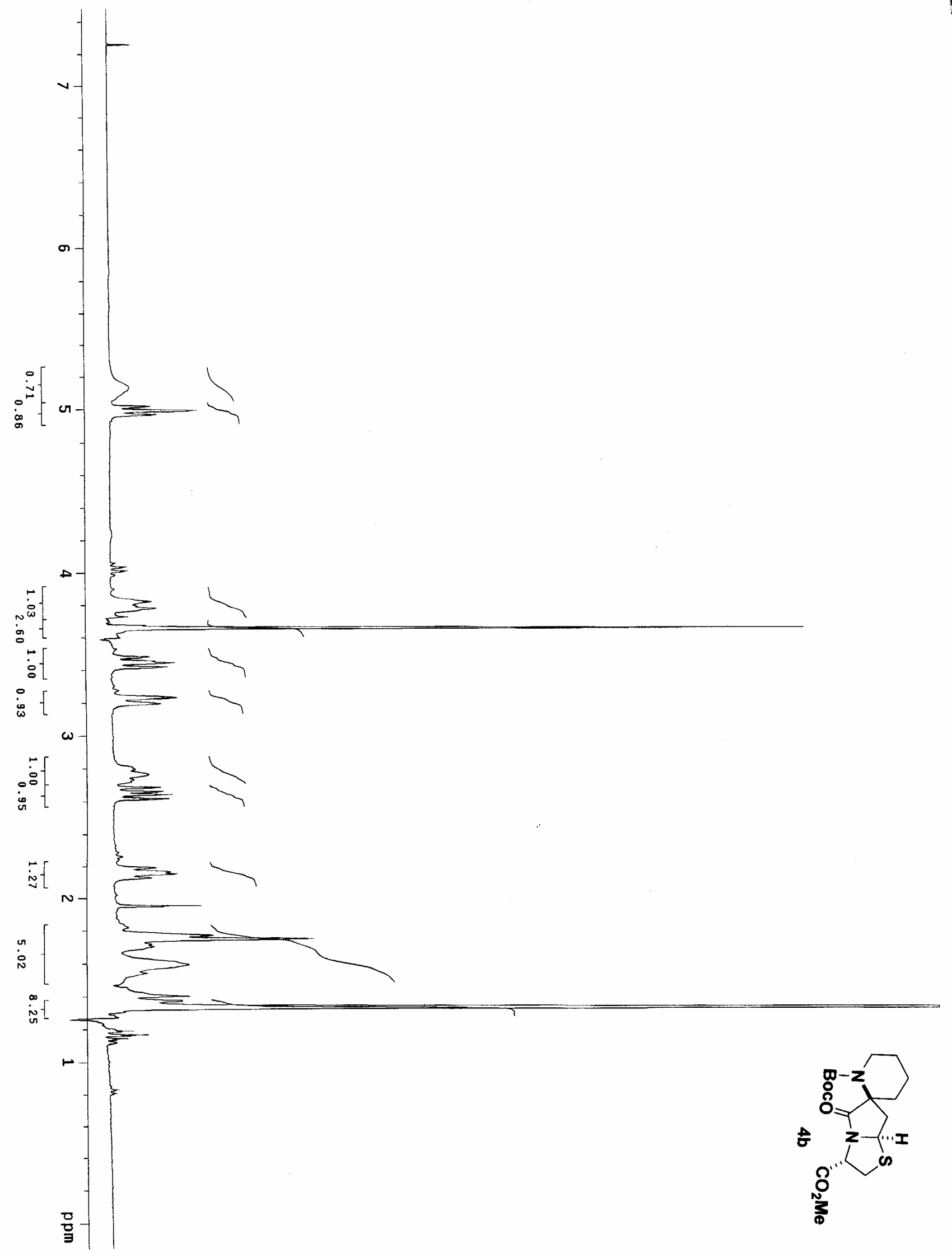




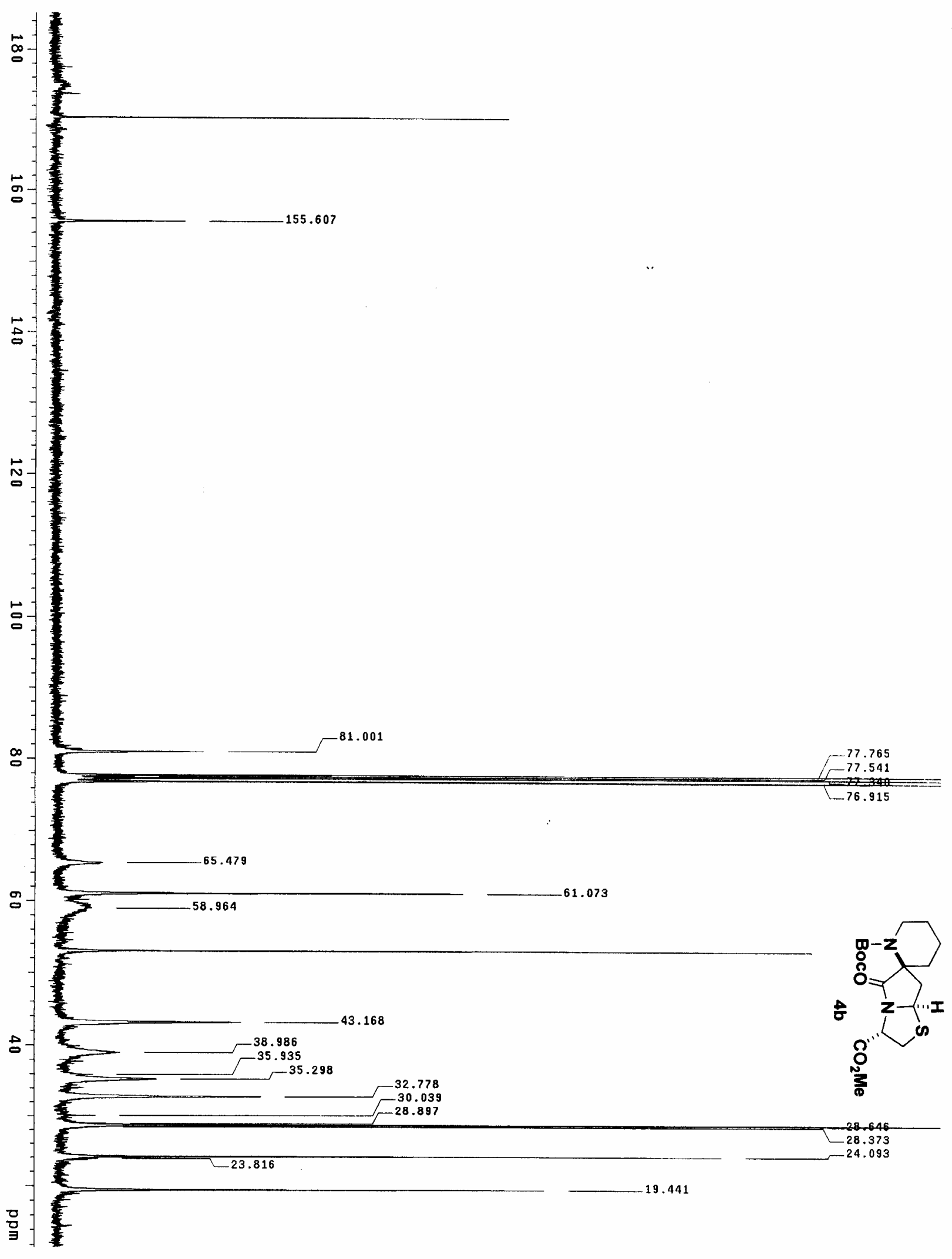




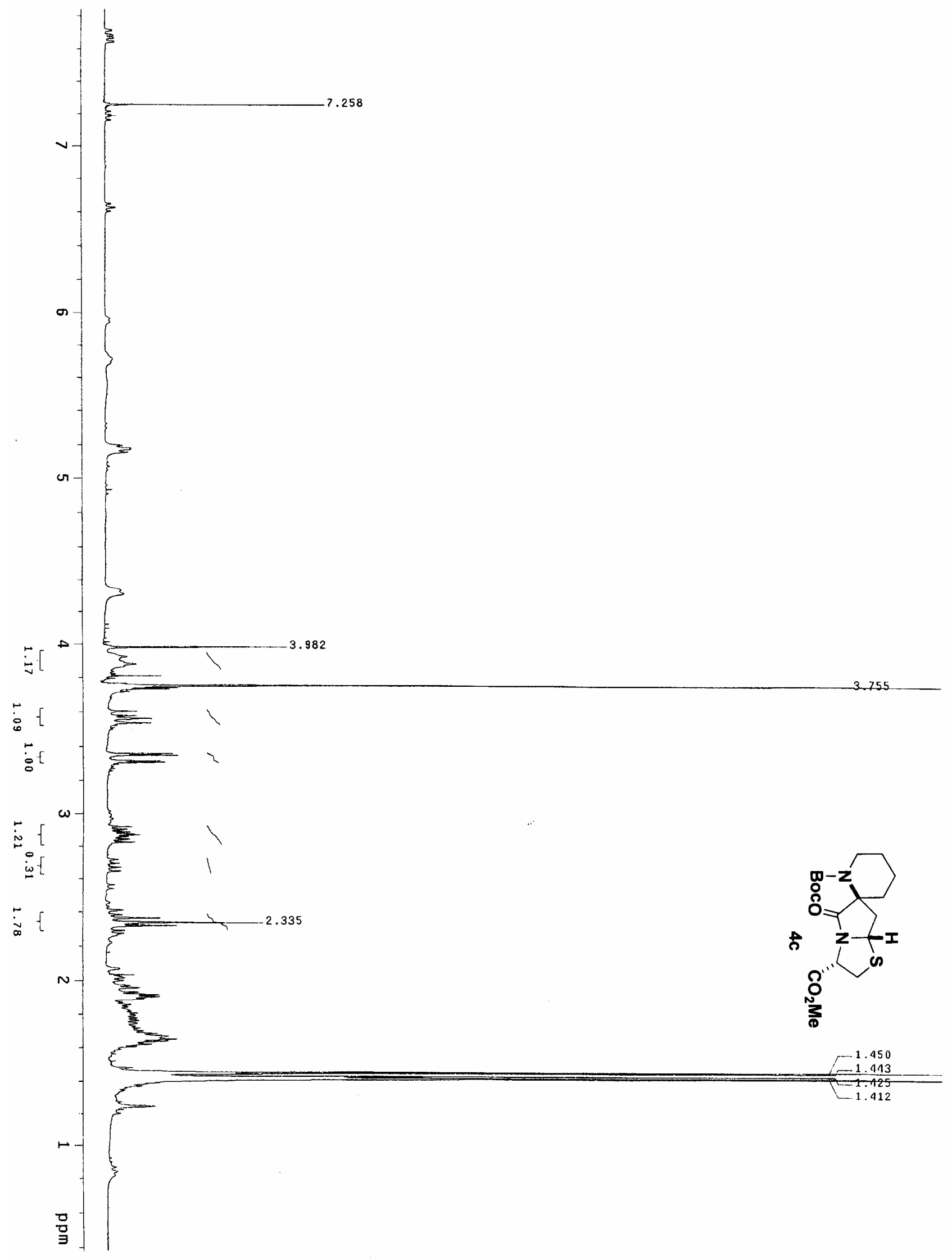




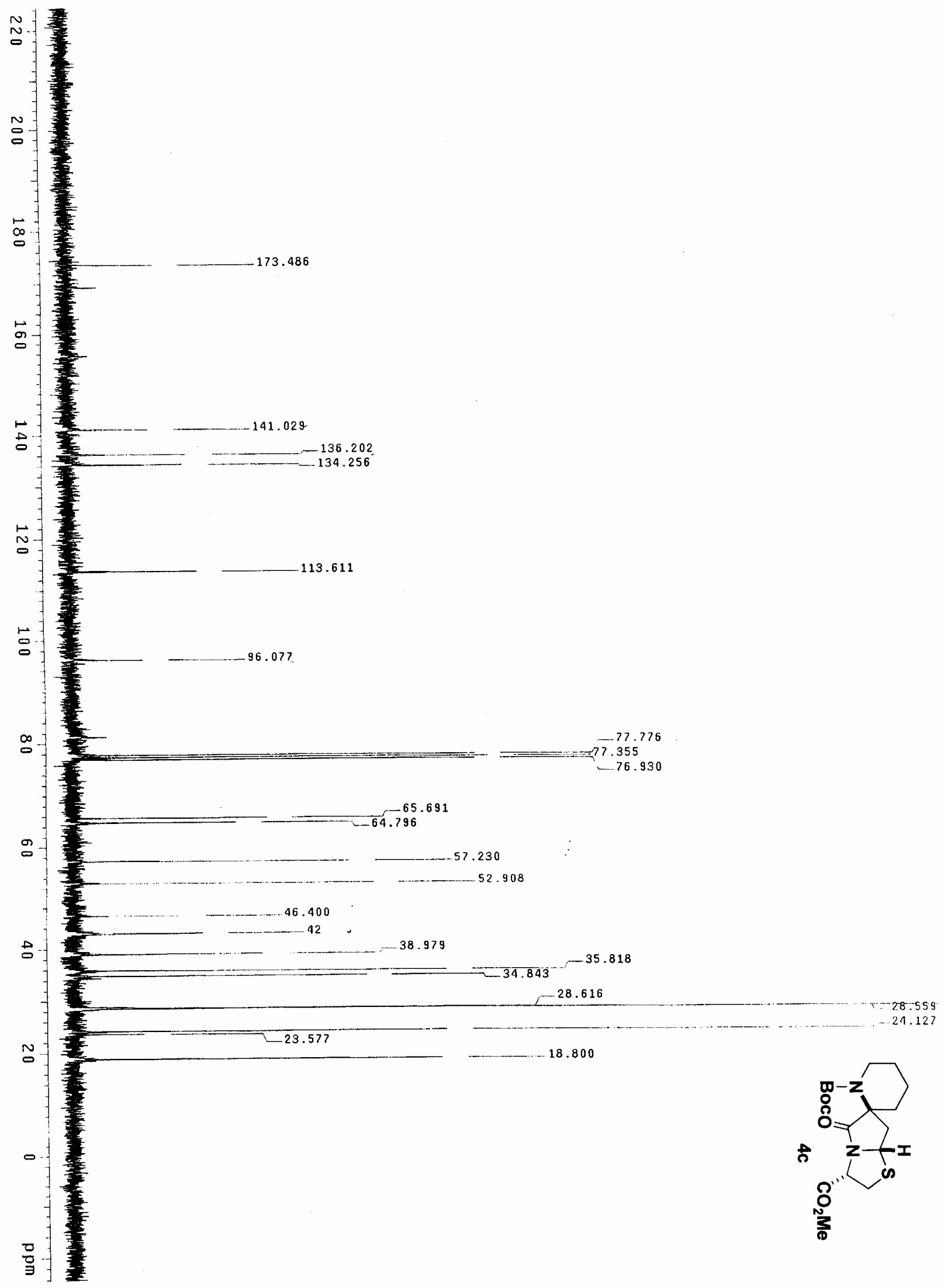




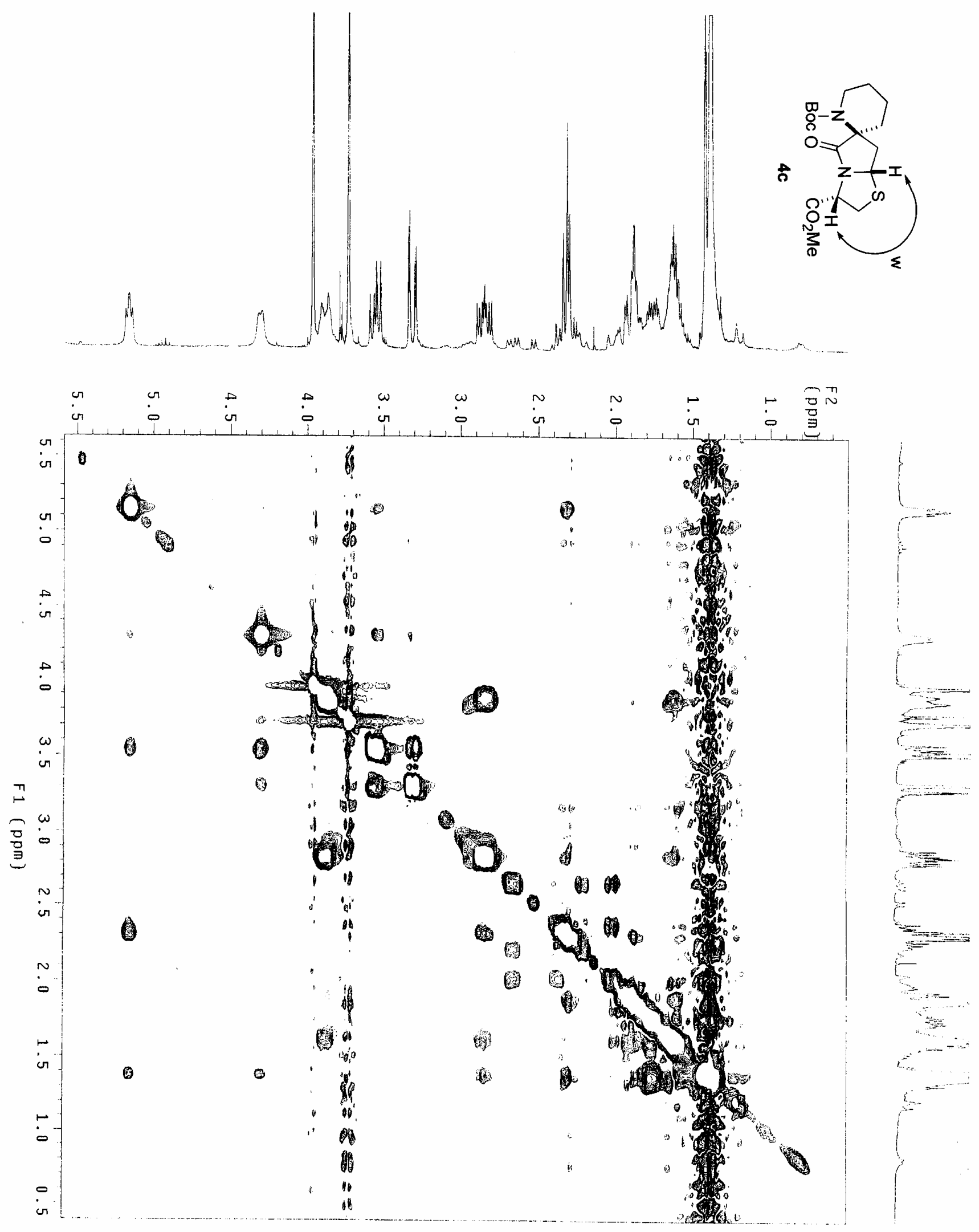




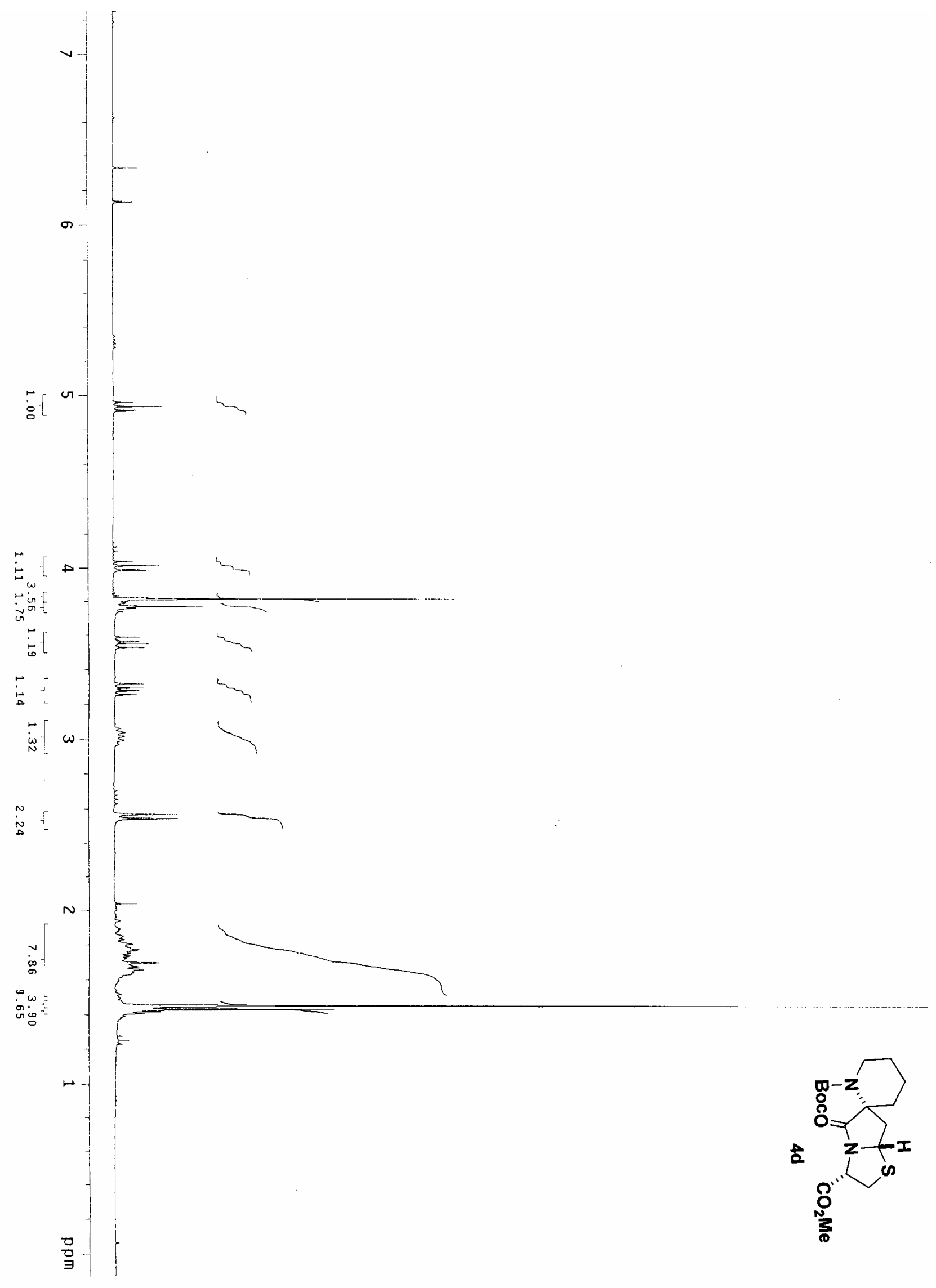




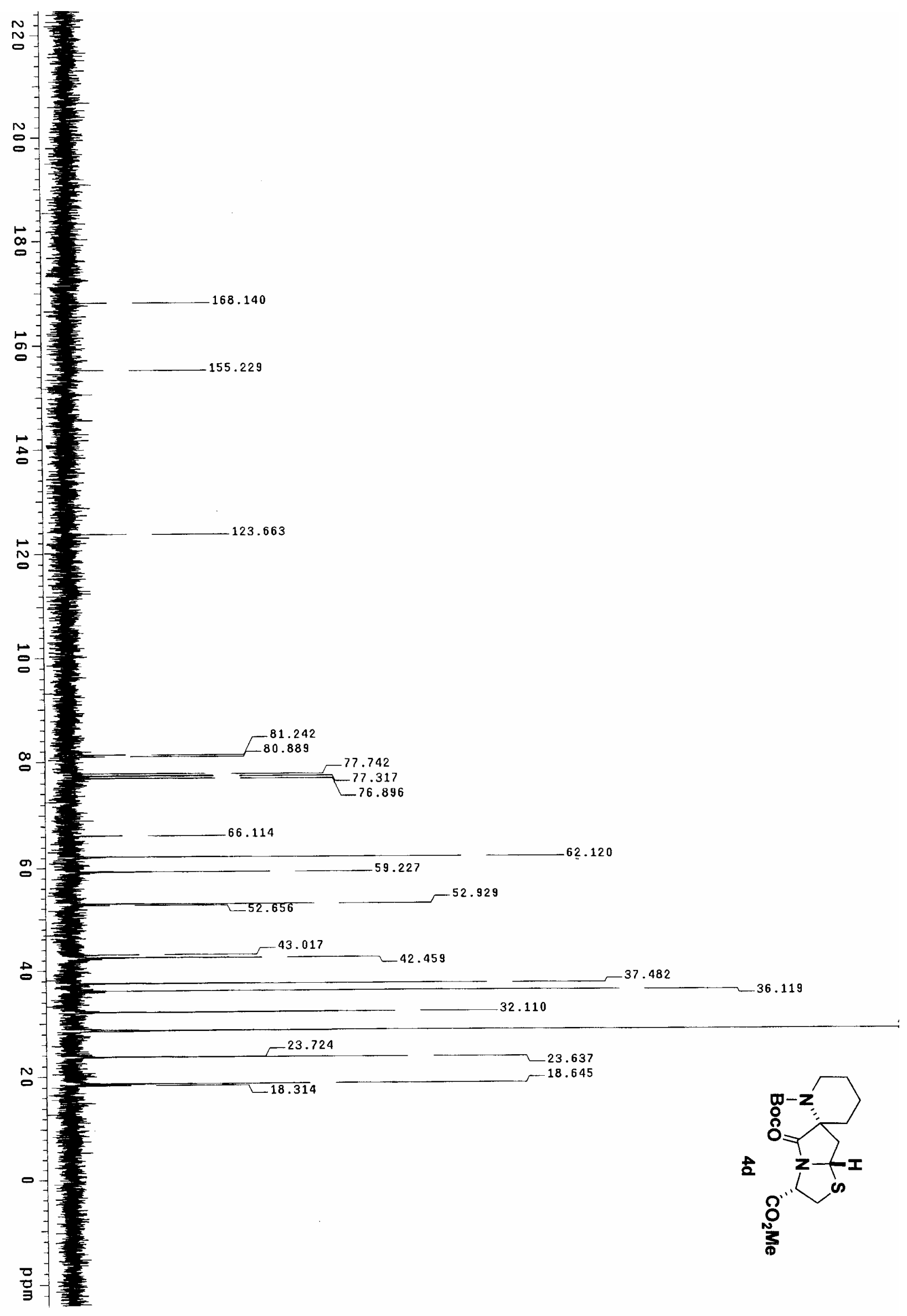




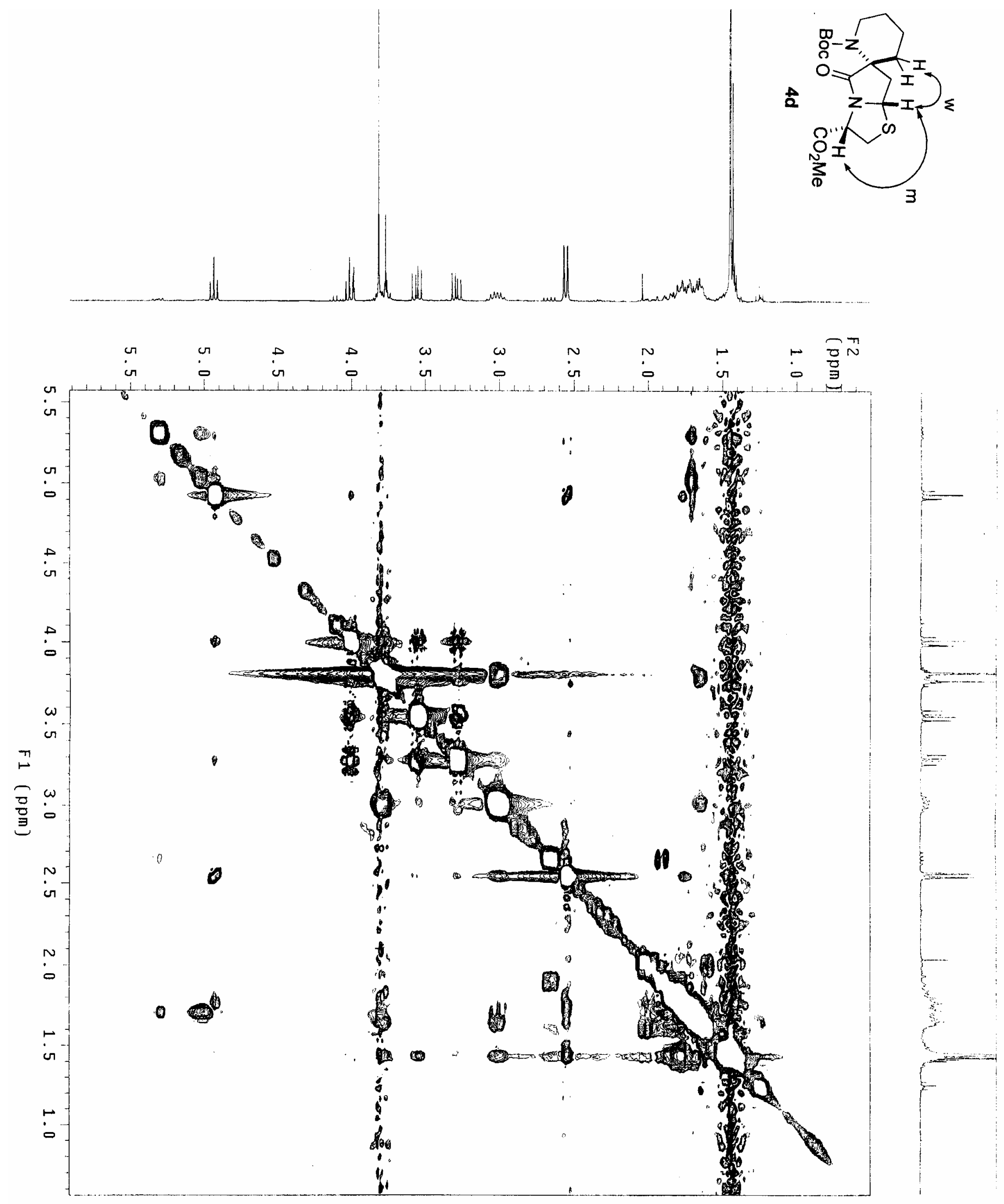




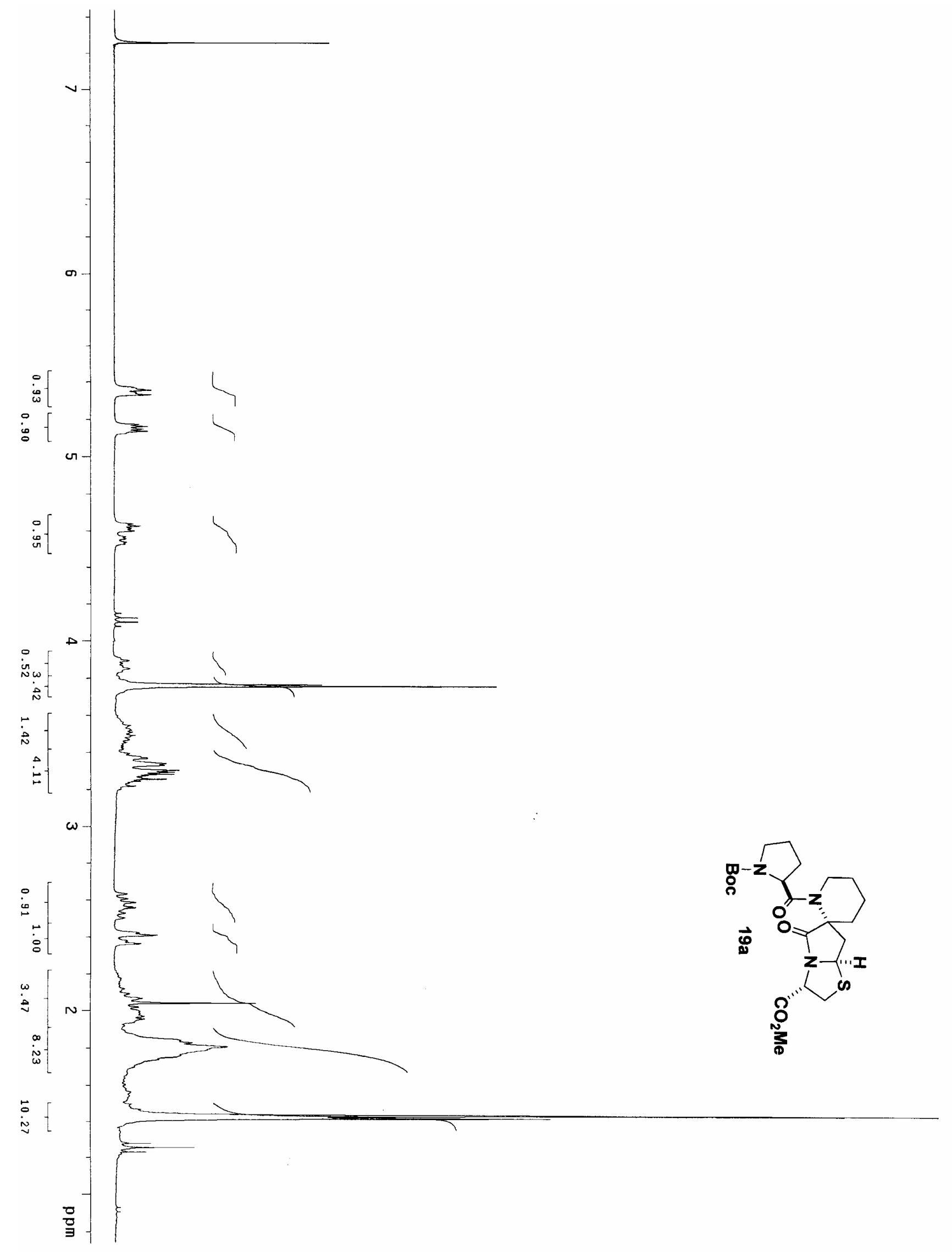




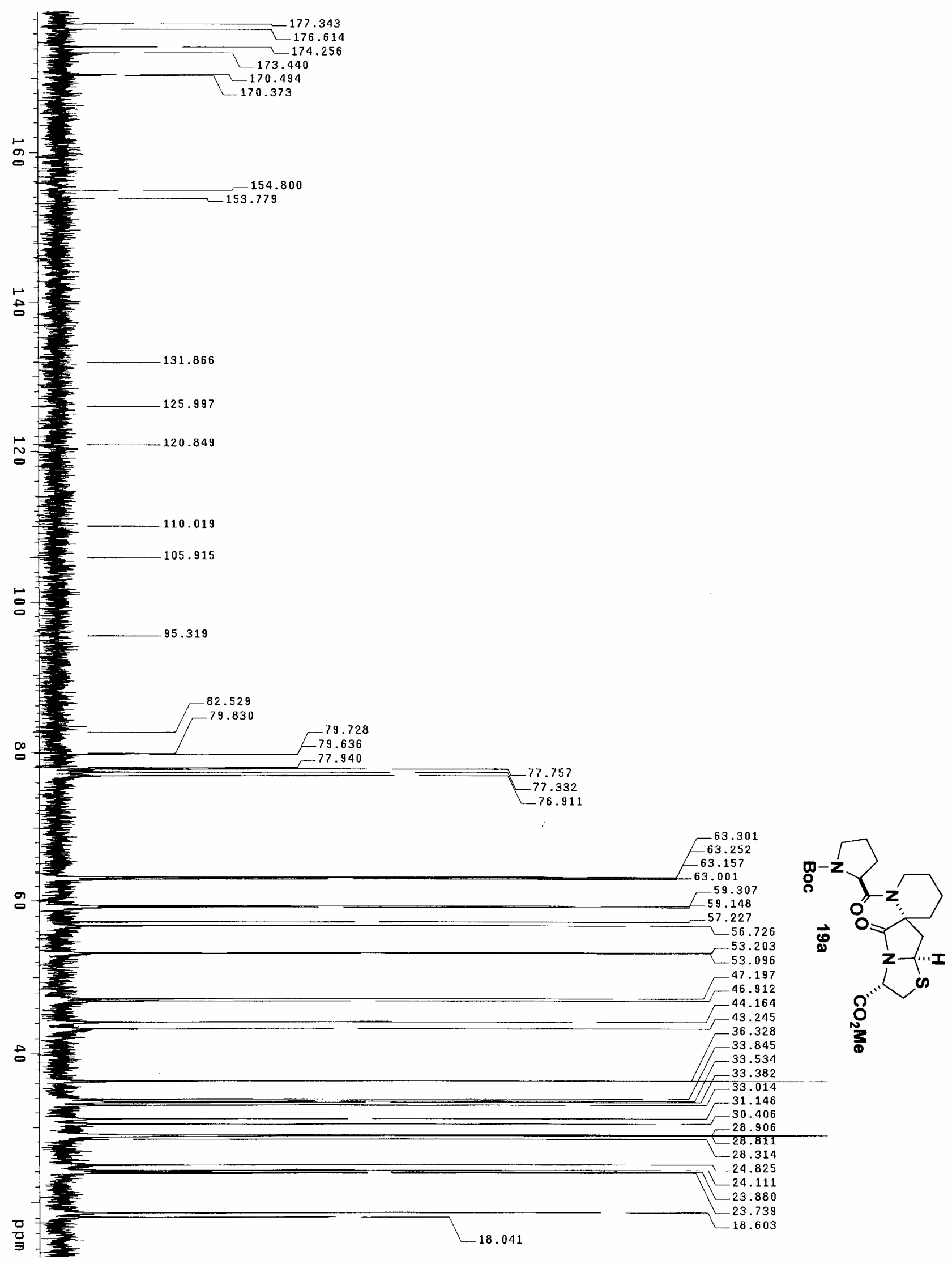




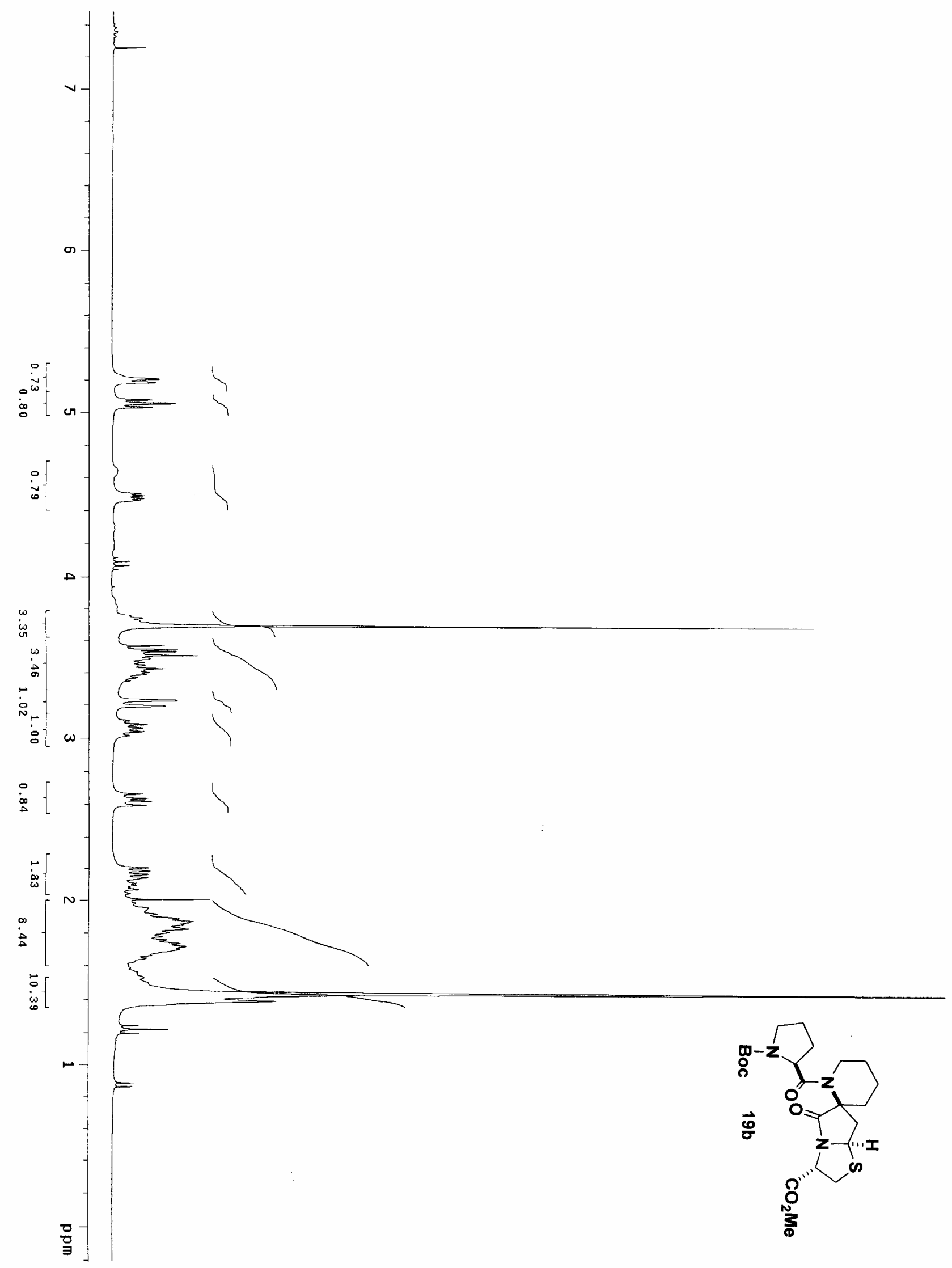




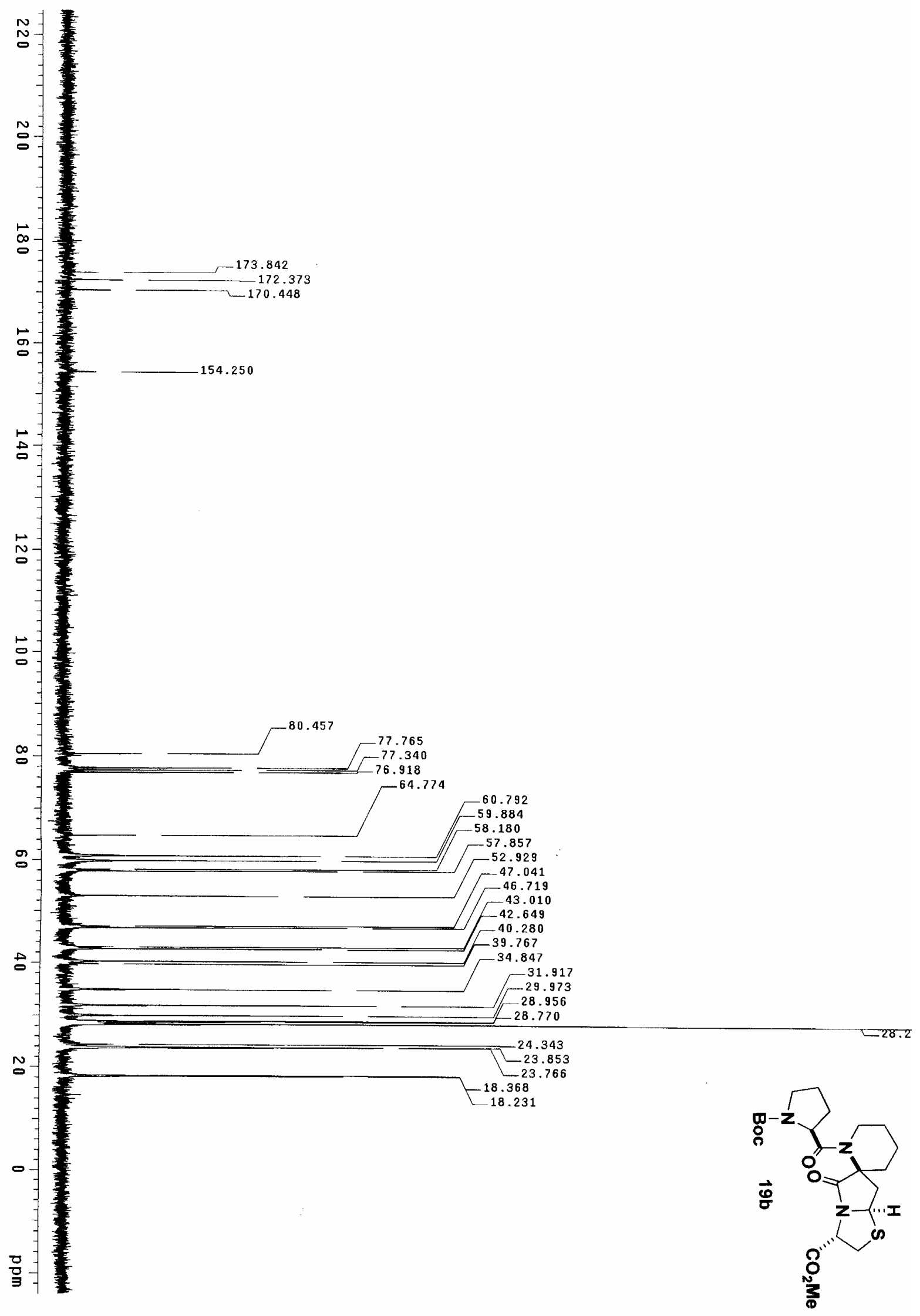




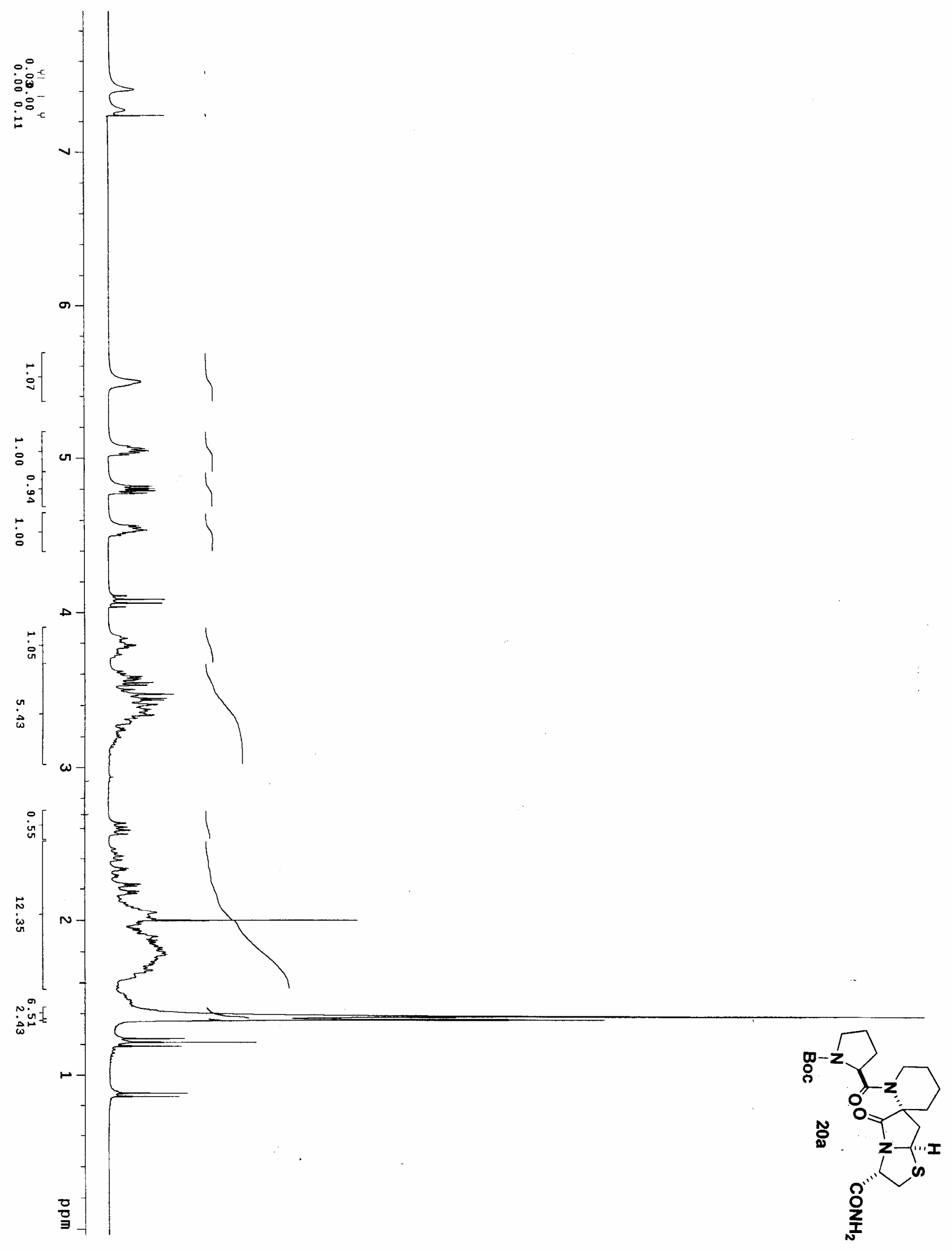




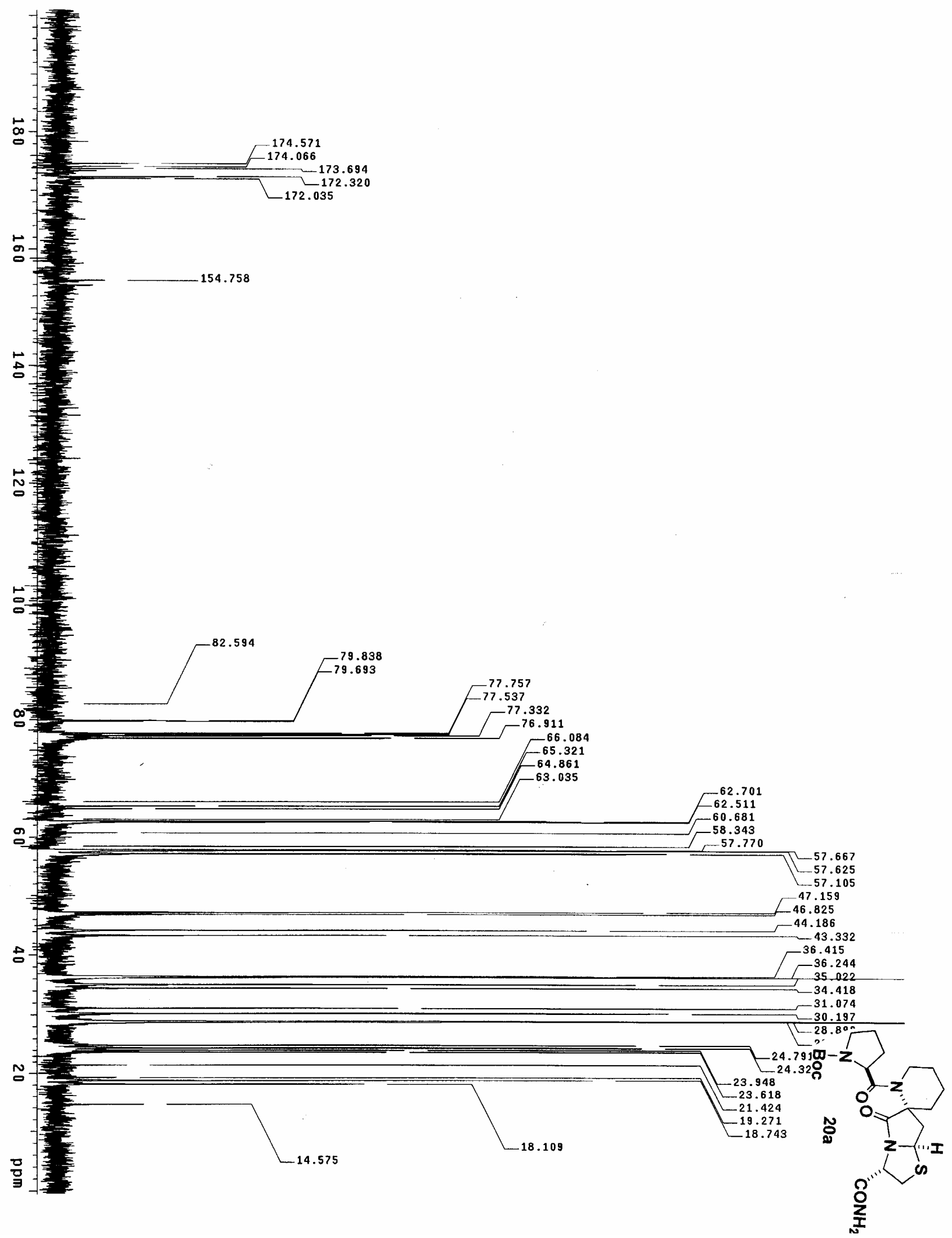




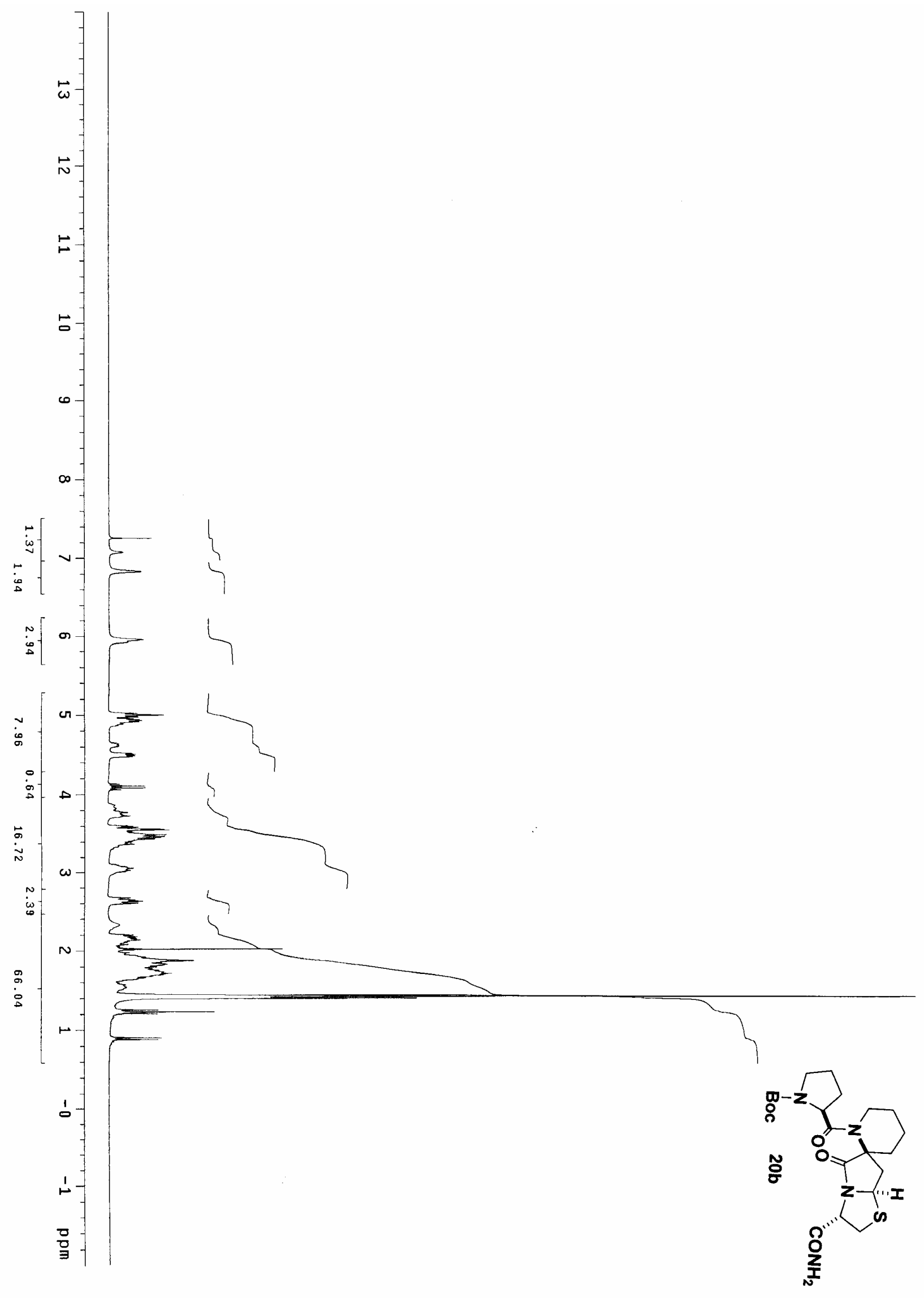




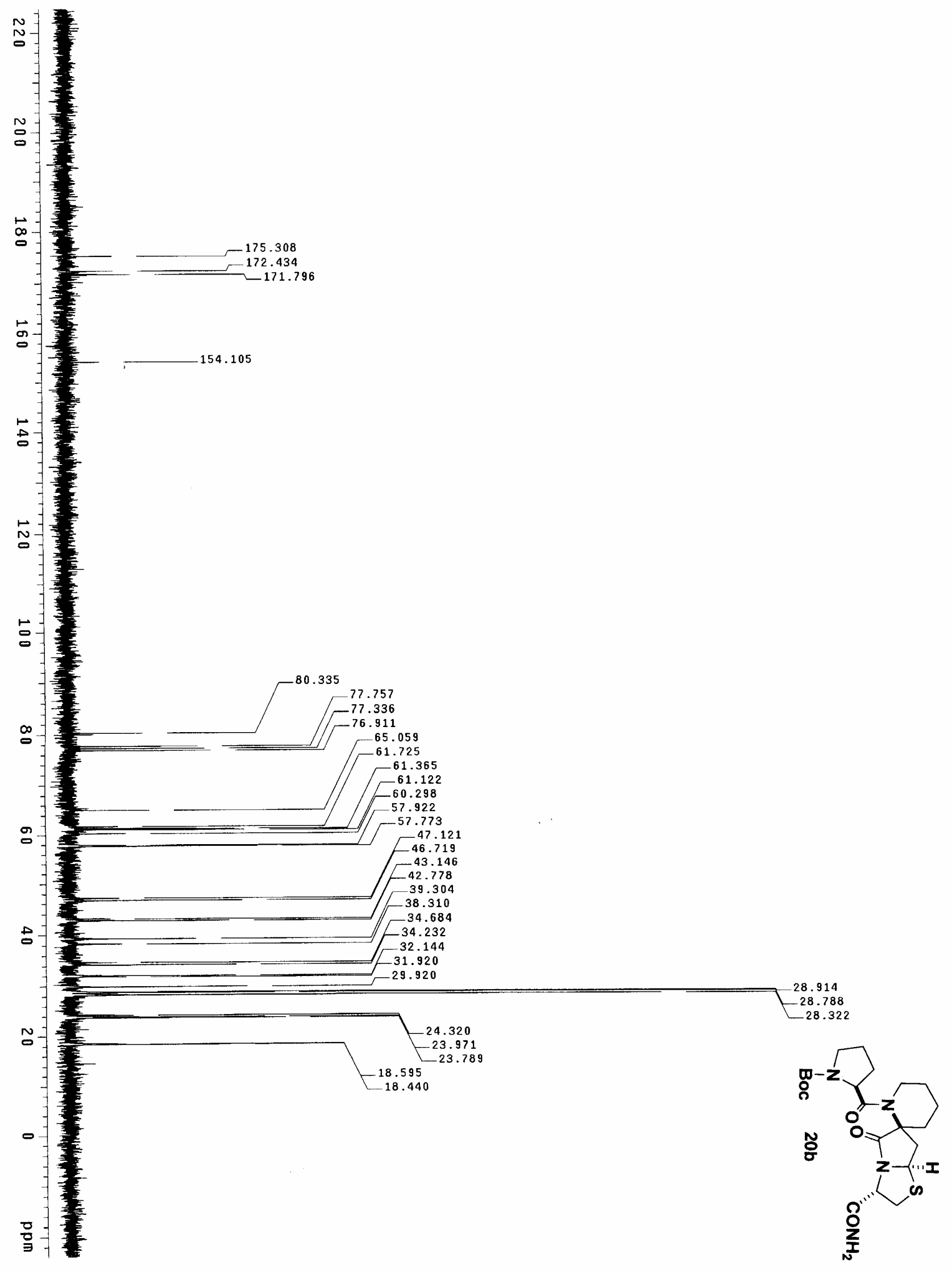




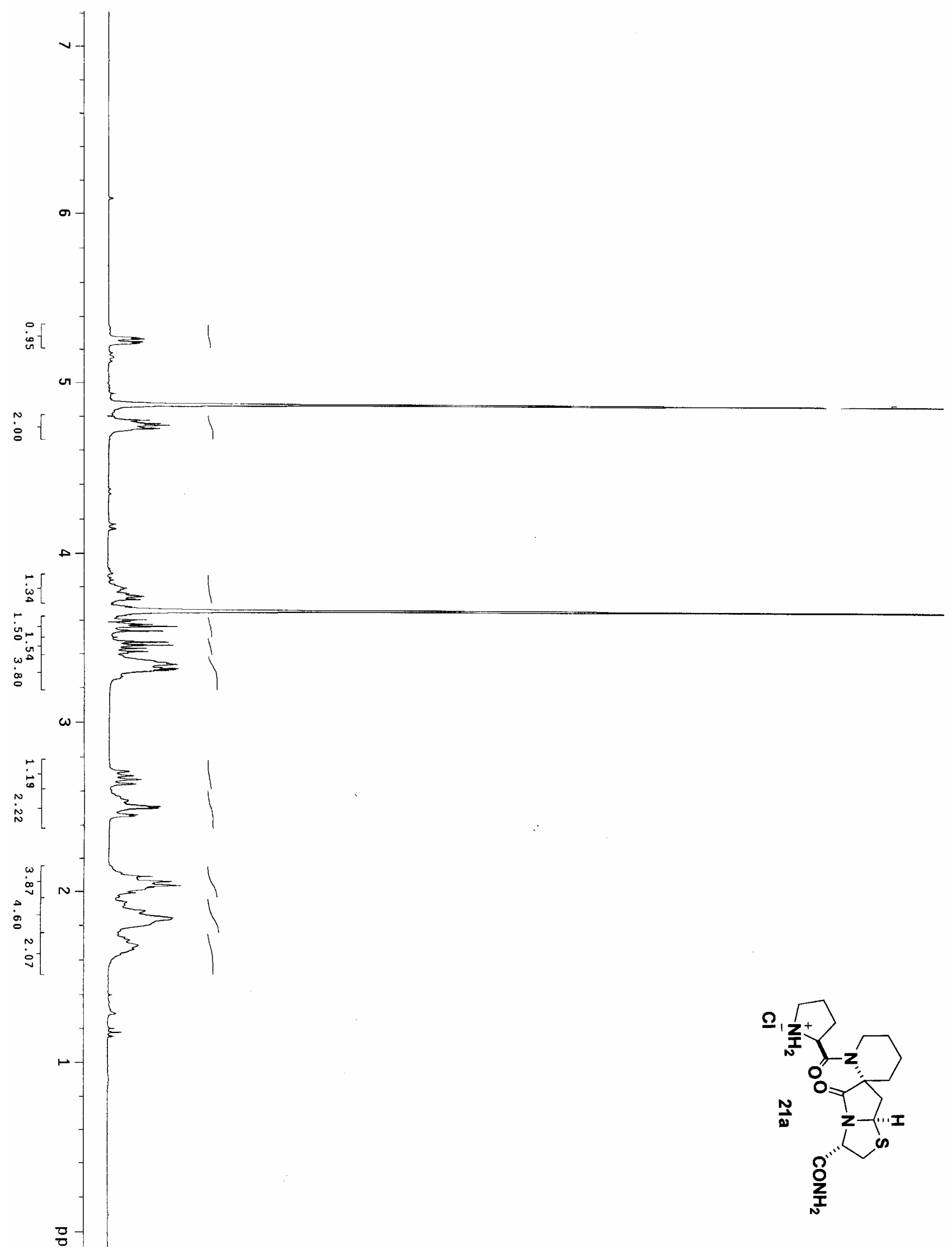




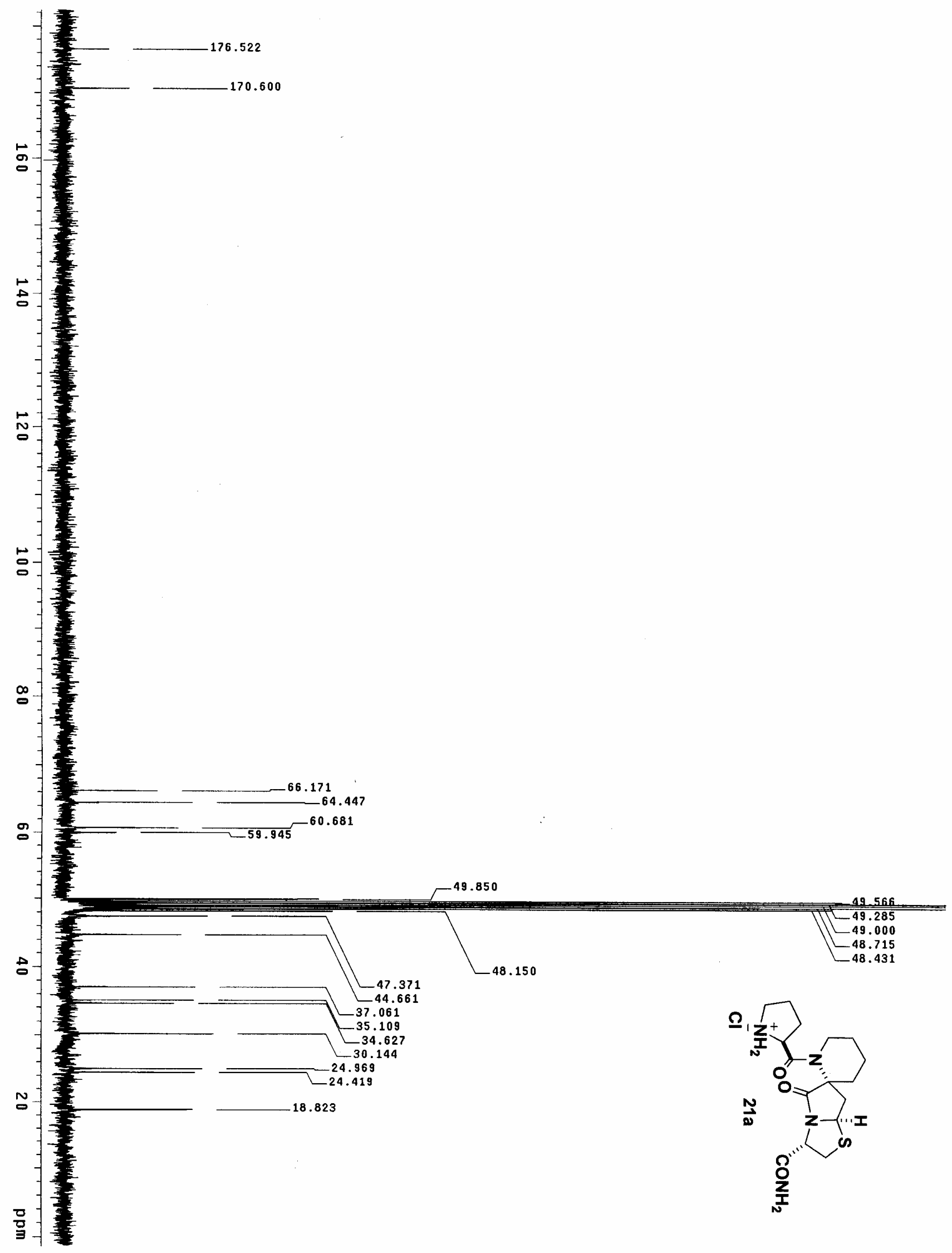




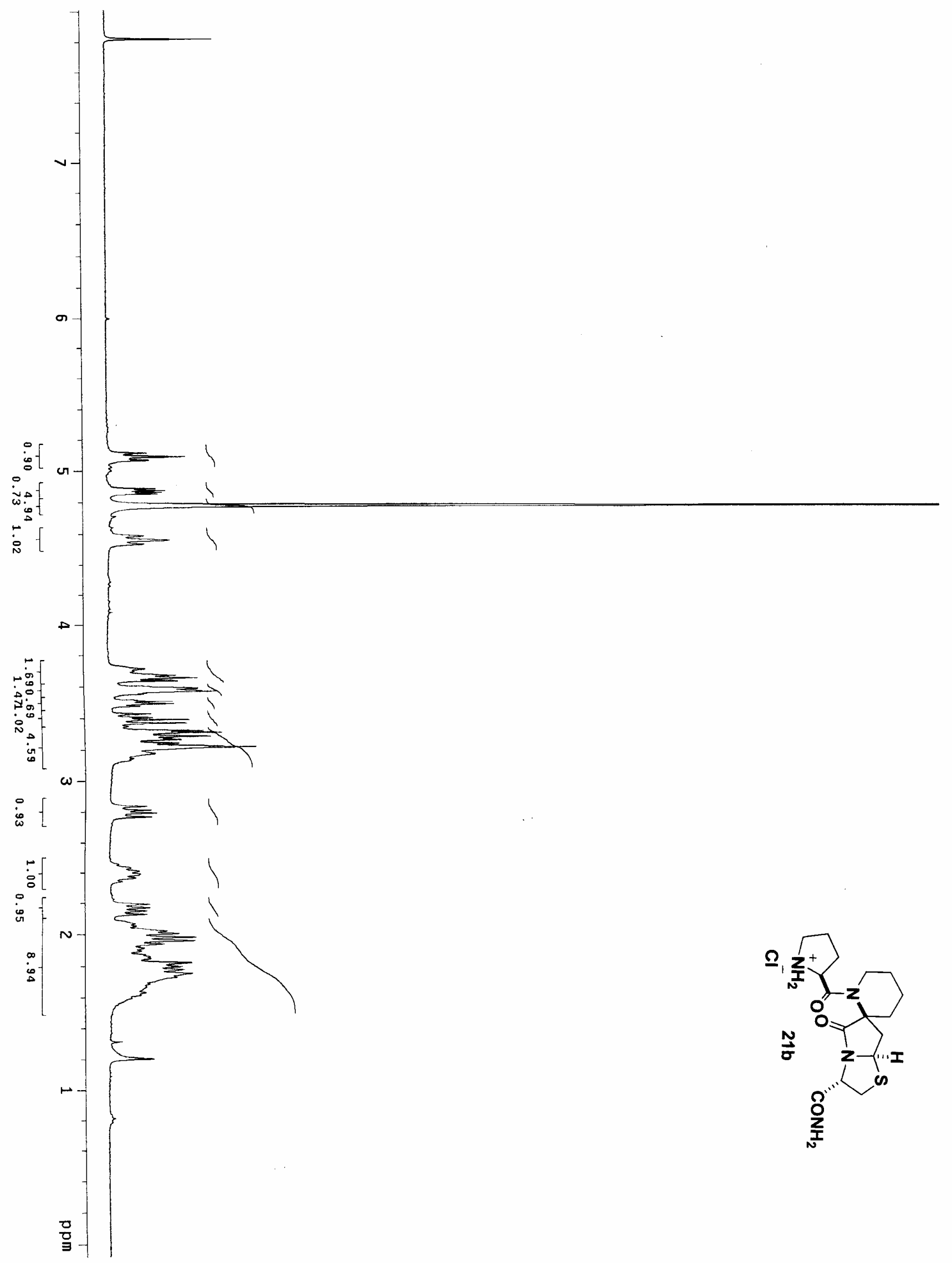




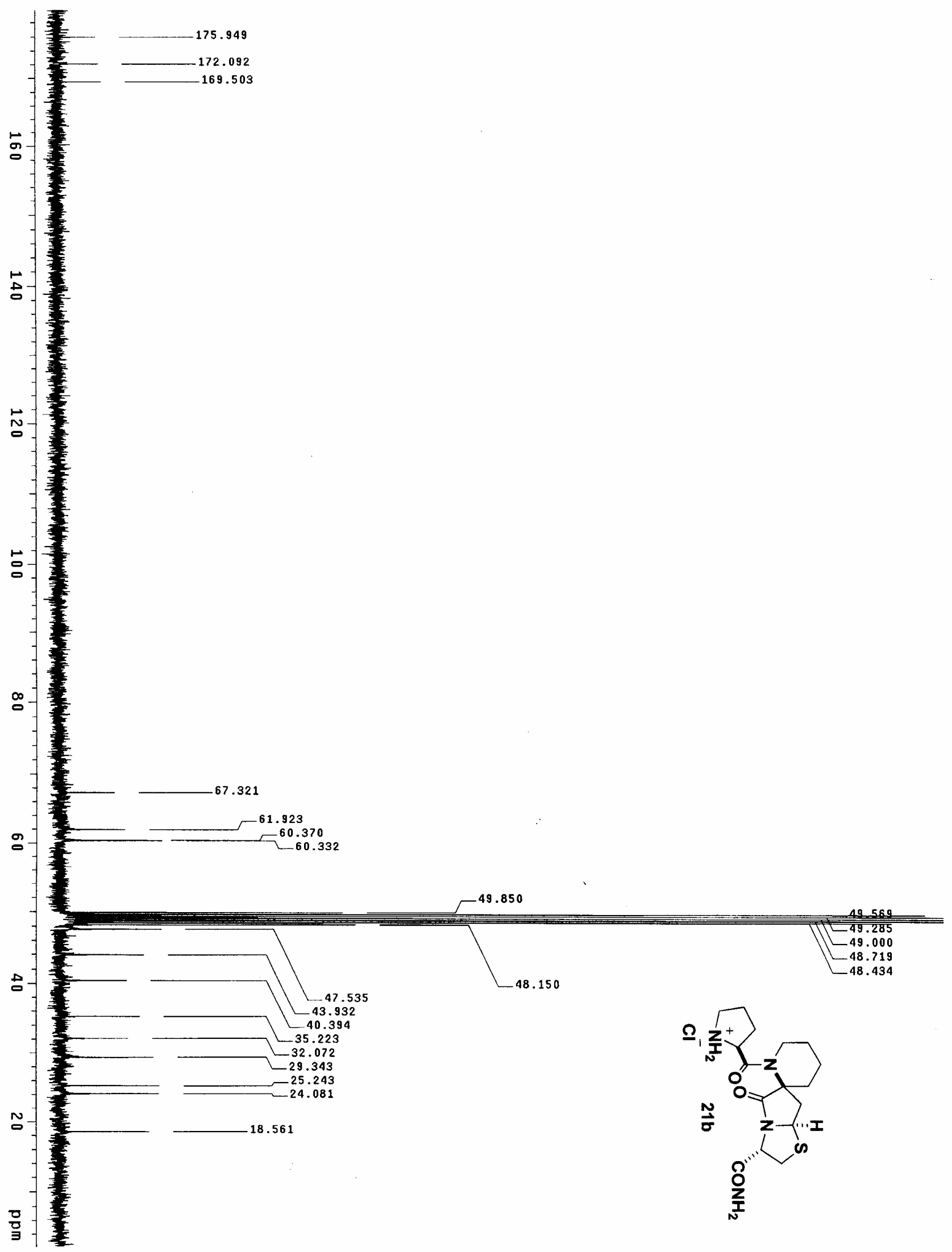




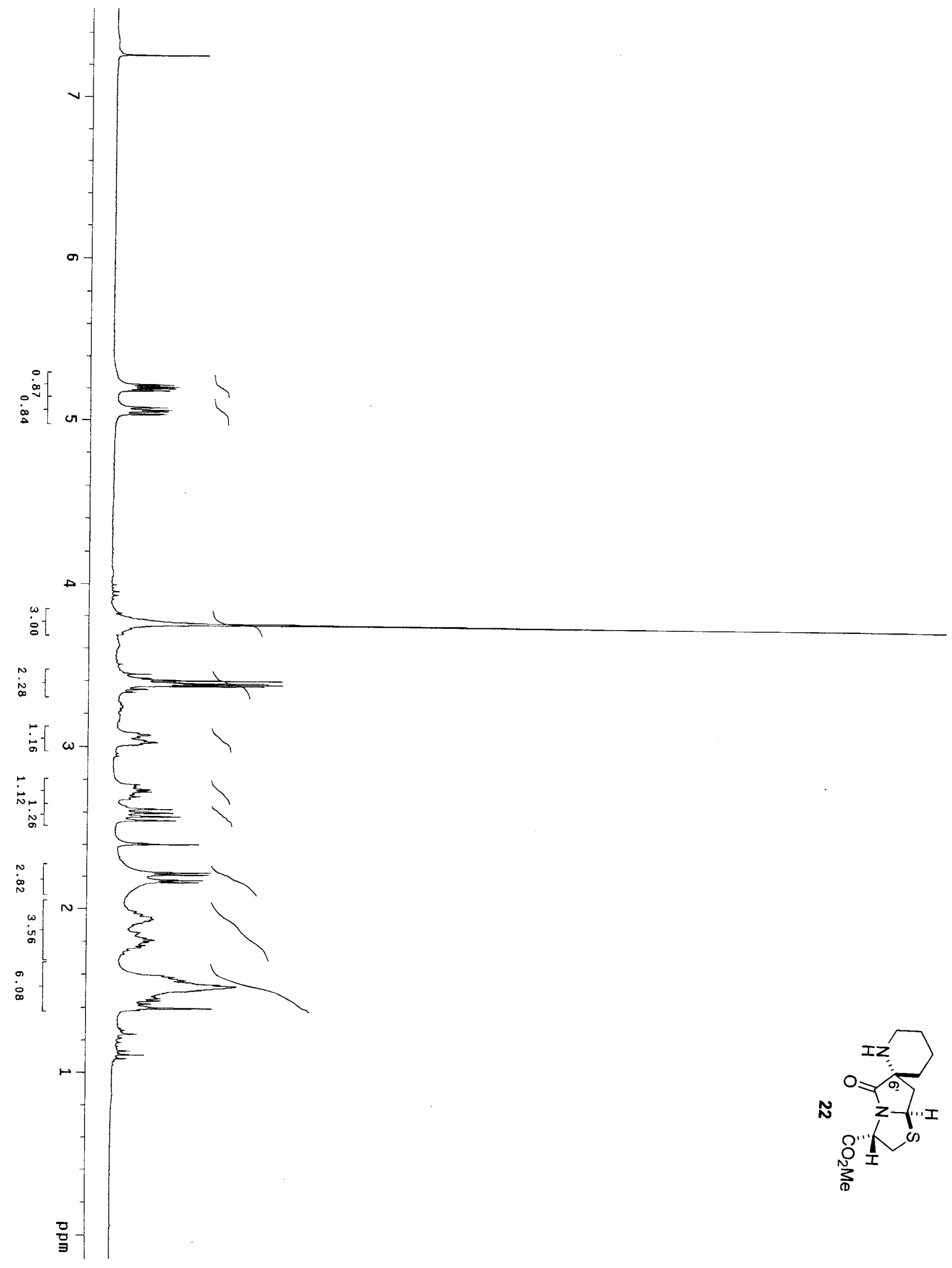




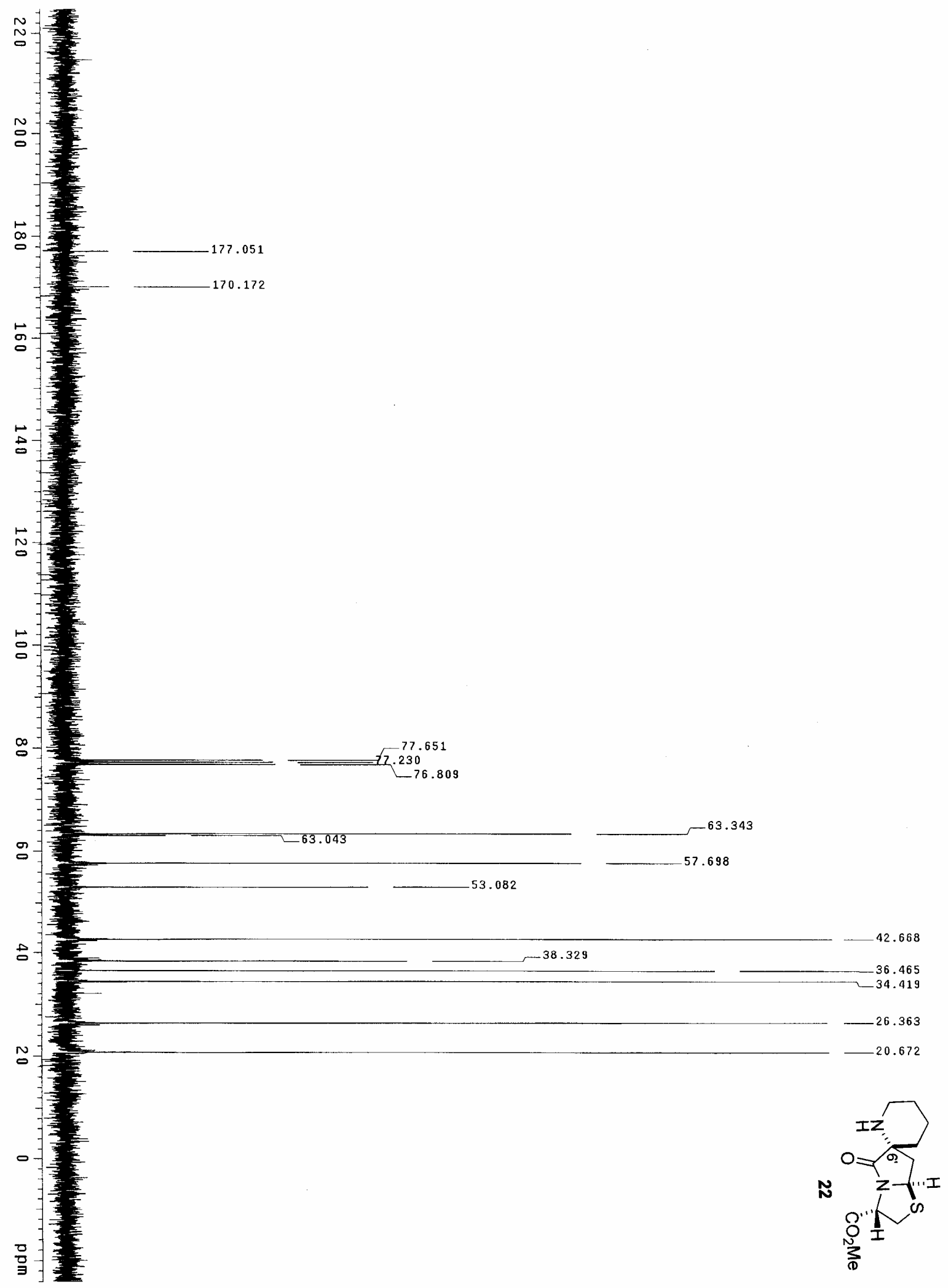




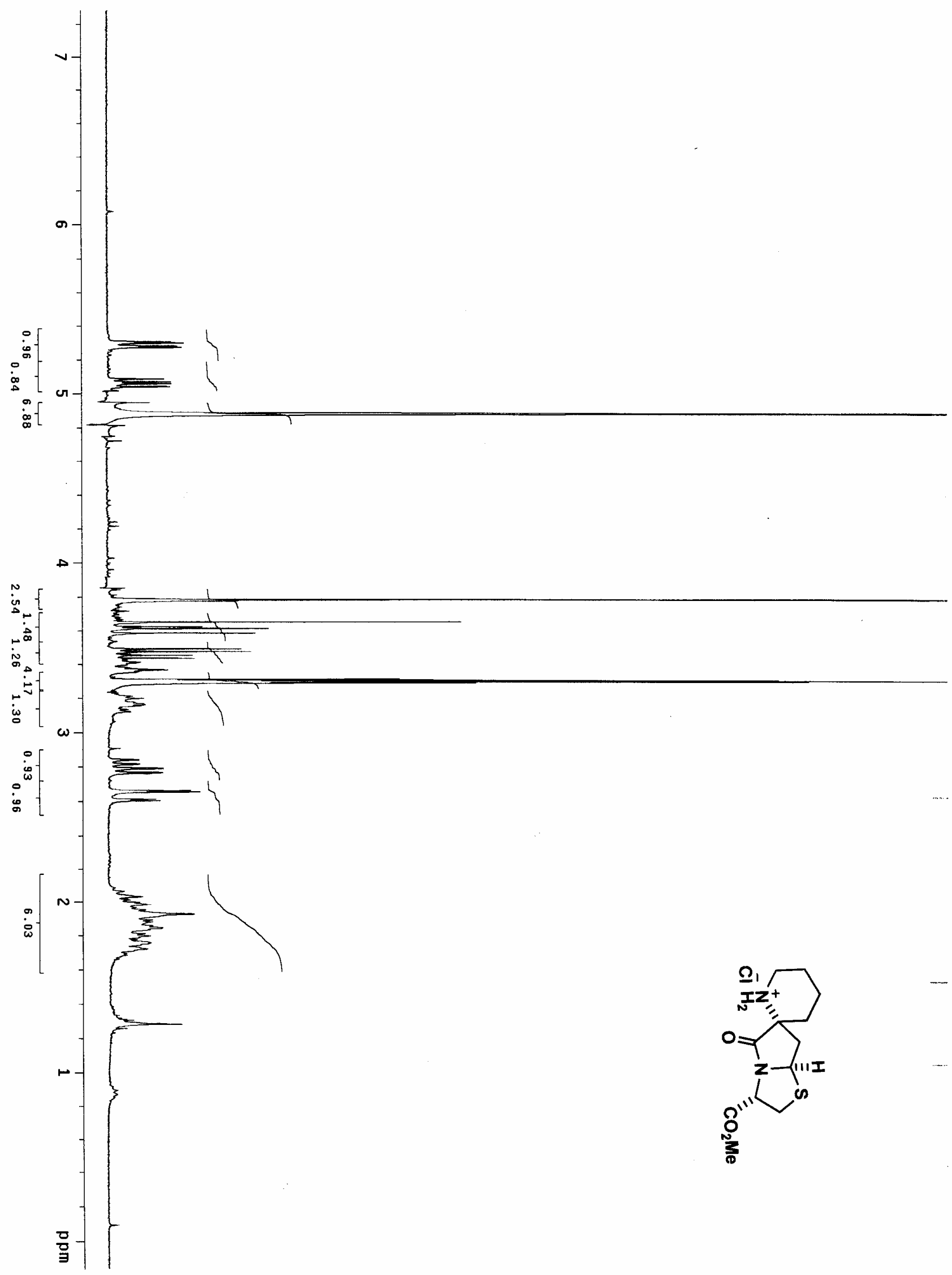




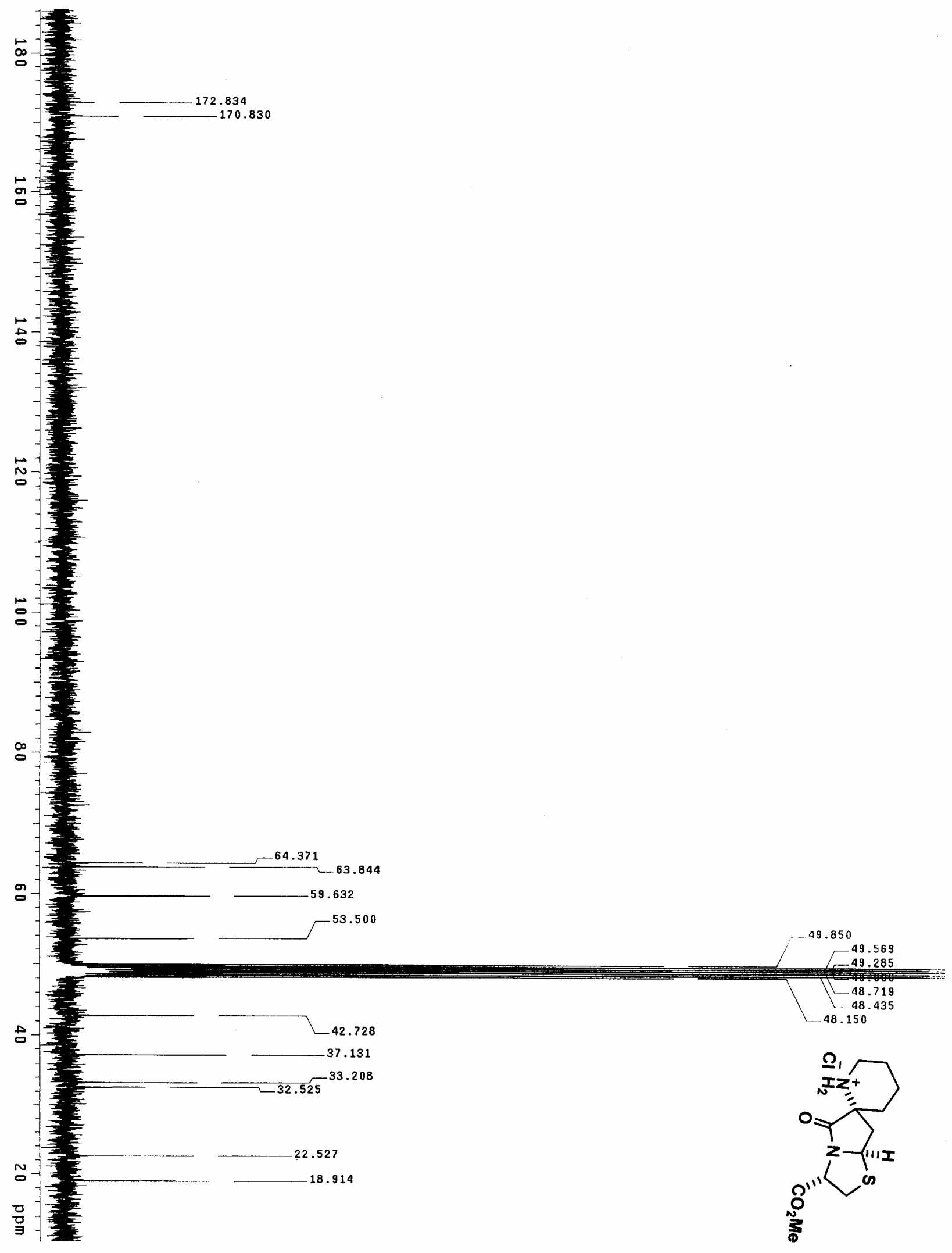




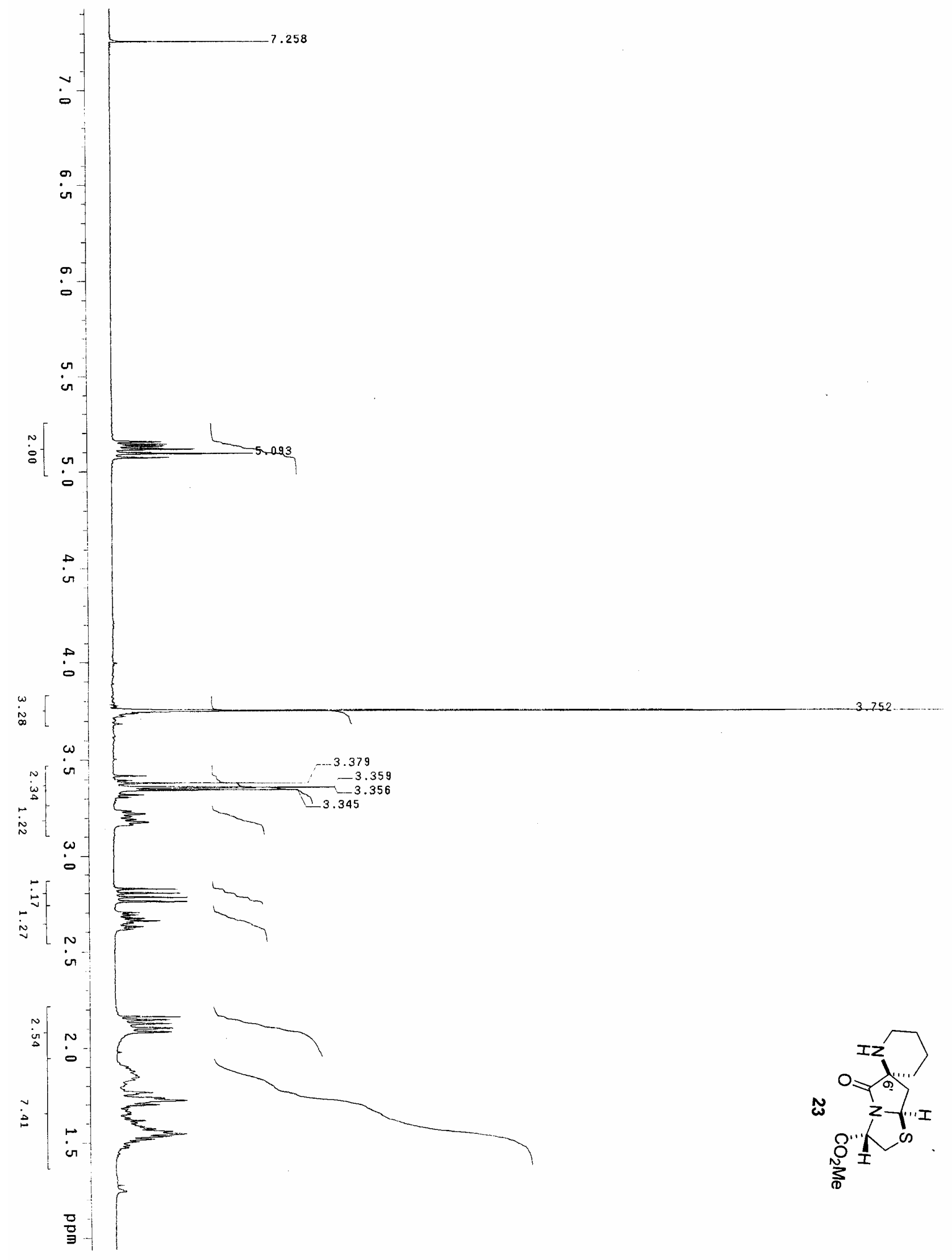



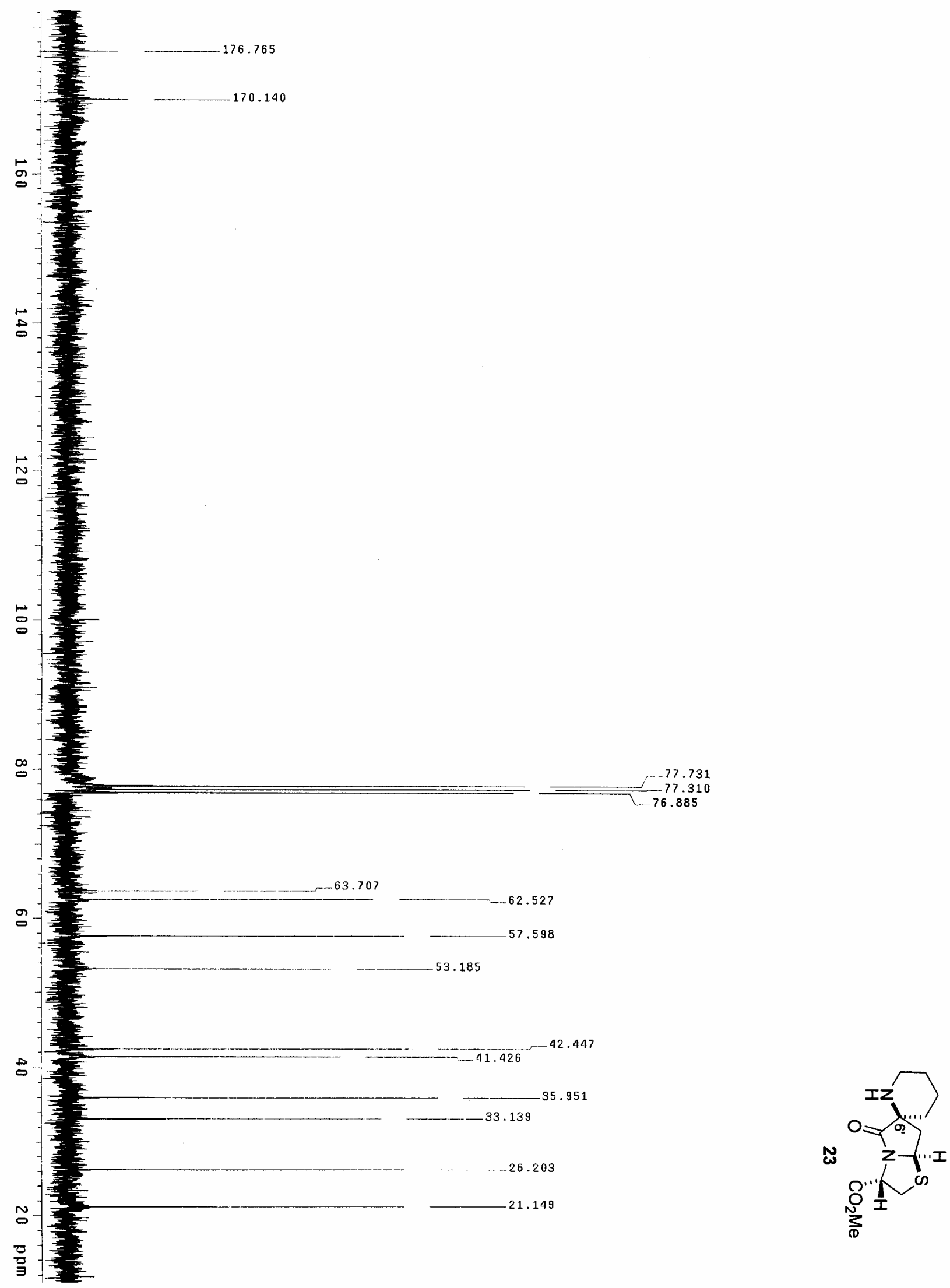


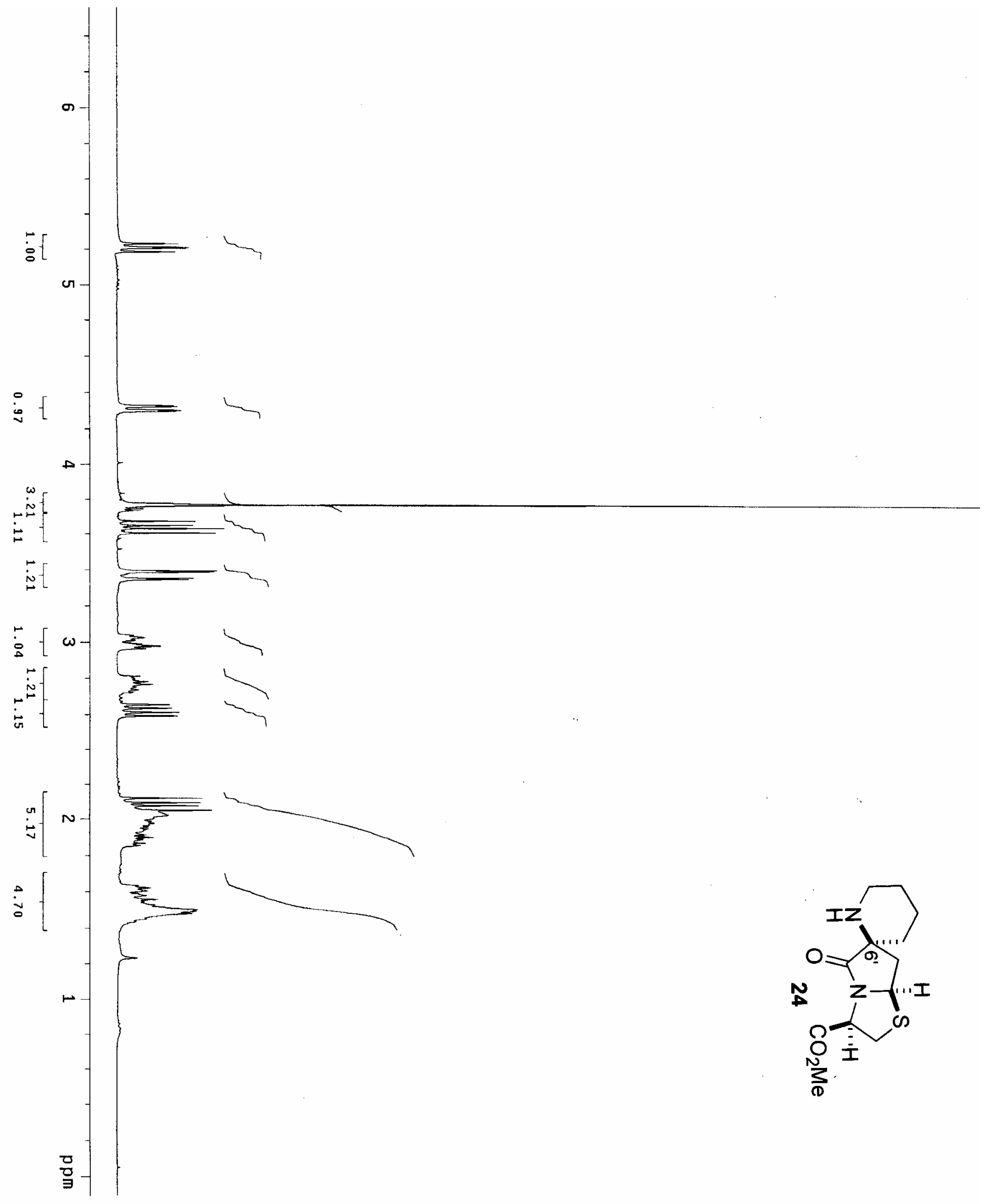




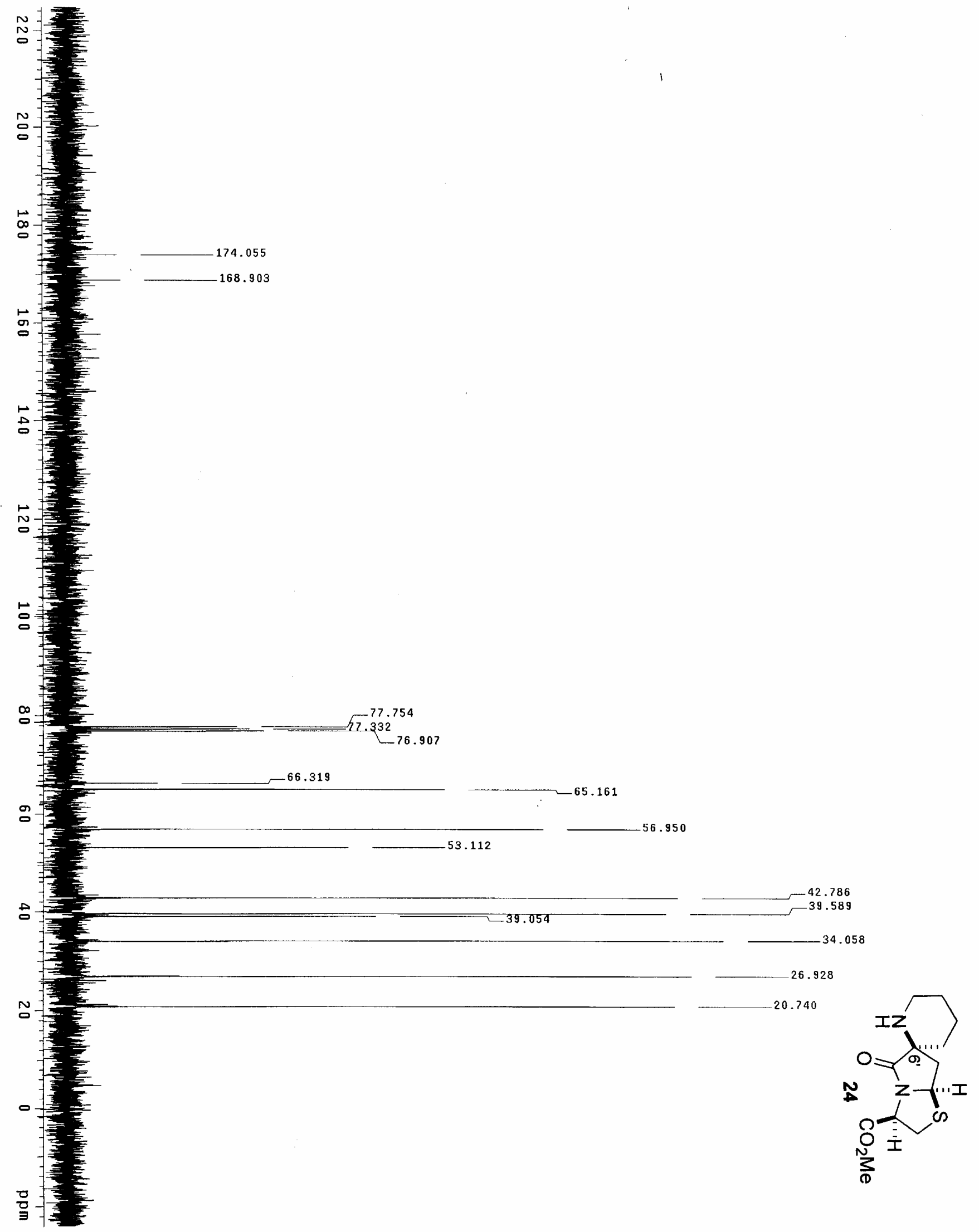



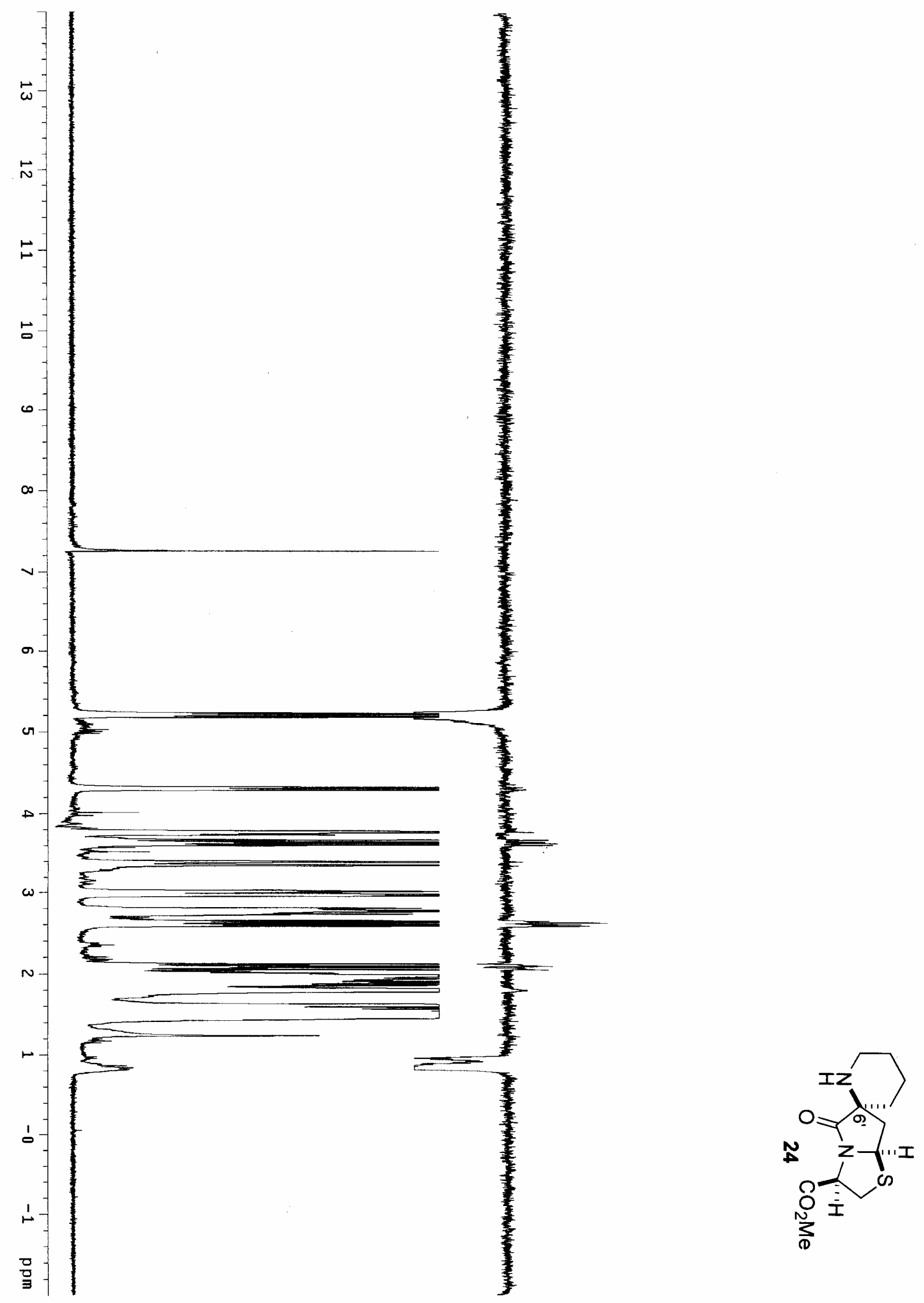


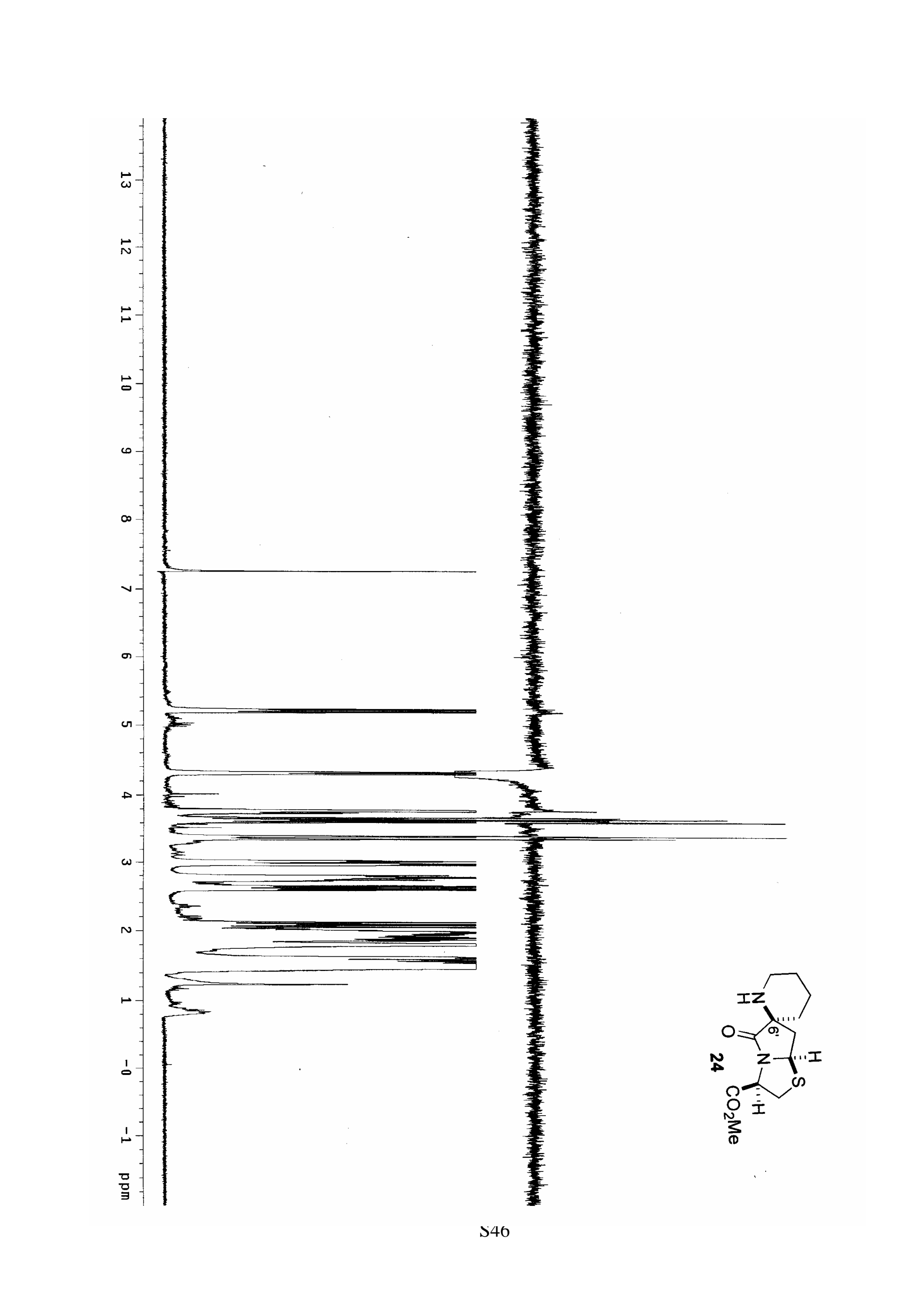

